\title{
Bio-optical modelling of primary production in the SW Finnish coastal zone, Baltic Sea: fast repetition rate fluorometry in Case 2 waters
}

\author{
M. Raateoja ${ }^{1, *}$, J. Seppälä ${ }^{1}$, H. Kuosa ${ }^{2}$ \\ ${ }^{1}$ Finnish Institute of Marine Research, PO Box 33, 00931 Helsinki, Finland \\ ${ }^{2}$ Tvärminne Zoological Station, University of Helsinki, 10900 Hanko, Finland
}

\begin{abstract}
A seasonal bio-optical monitoring programme was carried out in the SW Finnish coastal zone, Baltic Sea. Photosynthetic performance, spectral absorption characteristics, and fast repetitionrate (FRR) parameters of the phytoplankton community, as well as the natural light regime, were monitored 22 times from April to November. Primary productivity (PP) was determined with in situ fixation of ${ }^{14} \mathrm{C}$, as well as with bio-optical models based on either variable fluorescence parameters, or P-E dependence, or a combination of the two. Compared to the ${ }^{14} \mathrm{C}$-based model, the bio-optical models overestimated near the surface and underestimated in deeper layers, since bio-optical estimates of PP tend to follow the vertical pattern of irradiance, while in situ PP does not. The areal PP of the ${ }^{14} \mathrm{C}$-based model was $85.9 \mathrm{~g} \mathrm{C} \mathrm{m}^{-2} \mathrm{yr}^{-1}$, while the other models provided estimates 70 to $160 \%$ of this value. Seasonal variability in spectral light attenuation stressed the importance of spectral re-scaling of the photoadaptive variables $\alpha$ (maximum light-utilisation coefficient) and $\sigma_{\text {PSII }}$ (functional absorption cross-section of Photosystem II [PSII]). In order to describe the availability of light for photosynthesis, we calculated spectral scaling factors as the ratio of the light source of the FRR fluorometer or the P-E incubator to the in situ light field. The values were always above unity, with a maximum level of 2 for the P-E data, and as high as 3 for the FRR data, and varied seasonally and vertically. The apparent spectral mismatch between the light generated by the FRR fluorometer and the natural light field of the Baltic Sea suggests that spectral correction procedures should routinely be included in the FRR measuring protocol in Case 2 waters. Degradation of the fluorescence signal by ambient red light interfered with the FRR measurements in near-surface layers. We term this phenomenon the 'red light effect'.
\end{abstract}

KEY WORDS: Fast repetition rate fluorometry $\cdot$ FRRF $\cdot$ Primary productivity modelling $\cdot$ Spectral scaling · Bio-optics $\cdot$ Primary production $\cdot$ Phytoplankton $\cdot$ Baltic Sea

\section{INTRODUCTION}

One goal of modern biological oceanography is to gain a better understanding of primary productivity (PP) in various oceanic provinces, with special emphasis on eutrophication and climate change. Traditionally, the productive state of the sea is determined during field surveys. On a global scale this subject is most readily approached using remote sensing, because of its synopticity and large areal coverage. However, remotely-sensed ocean colour cannot provide ade- quate information about oceanic PP without the support of models (Babin et al. 1995), and by specific monitoring programmes providing the ground-truth data.

Bio-optical models, describing the distribution of light in the water column and the efficiency of the conversion of light energy into chemical energy by photochemistry, can be constructed using various tools. Photosynthesis versus irradiance parameters (Webb et al. 1974, Jassby \& Platt 1976) represent the basic dependence between algal productivity and incident light, and the parameters describing the P-E 
response (maximum light-utilisation coefficient $\alpha$ and light-saturation photosynthetic rate $P_{\max }$ ) are the pair of light-adaptive variables most utilised in bio-optical modelling (Smith et al. 1989). The main deficiency of the representativeness of P-E parameters lies in the fact that it is not possible to acquire results describing the exact state of the phytoplankton at the moment of sampling (Sakshaug et al. 1997). The shortcomings of the ${ }^{14} \mathrm{C}$ - and $\mathrm{O}_{2}$-techniques that have usually been used to determine P-E responses have been extensively treated by Marra (2002). The incorporation of spectral algal light-harvesting characteristics, based on absorption by all pigments or only photosynthetic pigments (e.g. Mitchell \& Kiefer 1988, Sakshaug et al. 1991), enables determination of the maximum quantum yield of photosynthesis (Bannister 1974, Kiefer \& Mitchell 1983) describing the intrinsic light-utilisation potential of the algal photosynthetic machinery. Still more accurate probing of algal light-utilisation characteristics is achieved by the photosynthetic action spectra (Lewis et al. 1985) and the spectral quantum yield (Schofield et al. 1990), describing spectral dependence of the P-E response and algal light conversion efficiency respectively. The above-mentioned parameters have been used, along with irradiance, as the basis of numerous bio-optical models to derive estimates of PP (e.g. Smith et al. 1989, Harding et al. 2002). As a summary of recent progress, Behrenfeld \& Falkowski (1997) presented a classification system for determining daily PP depending on the level of integration over depth/time/spectral scales.

Variable fluorescence metrics, and especially fast repetition-rate fluorometry (FRRF; Kolber et al. 1998), have increased knowledge about the biophysiology, photosynthetic efficiency and light-acclimation status of intact algae. Utilisation of FRRF metrics as the sole source for estimates of PP is, however, hindered by deviation observed between the photosynthetic electron flow and the fixation of $\mathrm{C}$ at high irradiance levels (Flameling \& Kronkamp 1998), and by the factors reflecting natural variability that are at present set as constants in the variable fluorescence theory (Kolber \& Falkowski 1993, Raateoja \& Seppälä 2001). Most research programmes (e.g. IronEx I, IronEx II, SOIREE) utilising FRRF metrics have been conducted in those parts of the world ocean where the underwater light regime is biased towards the bluish part of the spectrum, thus matching rather well with the excitation of the fast repetition-rate fluorometer (FRR fluorometer) (470 nm with $30 \mathrm{~nm}$ half-width). Perhaps because of this, the spectral scaling of the FRRF parameters has been given little thought, and only Suggett et al. (2001) have drawn attention to this issue. However, as the FRRF technique will undoubtedly be applied to more turbid aquatic systems, there is a need to clarify the actual effects of the accompanying spectral corrections on the FRRF parameters.

It is obvious - and has also been shown in several studies - that the photosynthetic parameters used in bio-optical models vary due to factors related to phytoplankton community structure and physiology (e.g. Babin et al. 1996, Stuart et al. 2000). Therefore, in order to improve the operational use of bio-optical models, there is a need to determine the variability in the photosynthetic characteristics of phytoplankton in different oceanic provinces (Platt \& Sathyendranath 1999), including our study area, the Baltic Sea. Consequently, in this study the seasonal photobiological characteristics of the resident phytoplankton were monitored in a near-coastal zone in the Baltic Sea, from the vernal bloom to late autumn. Our objectives were (1) to compare estimates of PP obtained from bio-optical models utilising P-E dependence, FRRF parameters, and algal spectral absorption characteristics with a PP model based on radioactively-labelled $\mathrm{C}$, and (2) to test the applicability of the FRRF technique in an environment that differs considerably in terms of spectral light attenuation from that of truly oceanic regions.

\section{MATERIALS AND METHODS}

Study area. The Baltic Sea is a non-tidal, semienclosed brackish-water basin characterised by a seasonal thermocline and a permanent salinity stratification (Voipio 1981). Optically, the Baltic Sea is classified as a Case 2 water body (sensu Morel \& Prieur 1977). Pronounced terrestrial impact leads to higher-thanoceanic concentrations of allogenic humic substances (Kirk 1994), and consequently to strong attenuation of underwater light (Kaczmarek \& Woźniak 1995). Furthermore, the waters of the Baltic Sea are optically inhomogeneous due to patchiness caused by high concentrations of suspended matter (Sagan \& Dera 1994).

The seasonal phytoplankton dynamics in the Baltic Sea are characterised by a pronounced vernal bloom period, with diatoms and dinoflagellates as the dominant groups, a subsequent nutrient-limited mid-summer minimum phase with an increased fraction of algal biomass comprised of picoplankton (Kuparinen \& Kuosa 1993), and recurrent late-summer algal blooms usually dominated by diazotrophic filamentous cyanobacteria (Kononen et al. 1996).

A supply of inorganic nutrients from the aphotic zone is important for the summertime ecosystem dynamics at the entrance to the Gulf of Finland. Particularly, the coastal zone of the east-west aligned Hanko peninsula (our study site; Fig. 1) is a well-known upwelling area, where southerly to westerly winds tend to trigger this phenomenon (Haapala 1994). Moreover, the entrance 
to the Gulf of Finland is characterised by a quasi-permanent frontal system between the more saline waters of the open Baltic Proper and fresher waters flowing from the Gulf of Finland (Kononen et al. 1996).

In summary, our study site is part of a non-steadystate oceanic system from an algal ecological point of view, with a pronounced spatial, vertical and temporal variability in phytoplankton species composition and biomass (Kononen et al. 1999), thus making any attempt to resolve seasonal trends in biological activity extremely challenging.

Sampling station. Sampling and field measurements were carried out at station 'Längden' $\left(59^{\circ} 46^{\prime} \mathrm{N}\right.$, $23^{\circ} 15^{\prime} E_{i}$ Fig. 1) approximately 4 nautical miles off the coast in the tension zone between the Hanko archipelago and the pelagic. We sampled over a total of 22 station days between 11 April and 15 November 2000 henceforth referred to as Stns 1 to 22 (see Table 2). Sampling and incubations were carried out between 9:00 and 11:00 h local time. At Stn 11, due to strong wind, the sampling was carried out near the island of Långskär in the outer reaches of the Hanko archipelago.

Sampling and hydrography. Discrete water samples were taken with a limnos-sampler from depths of 0,3 , 6,9 , and $15 \mathrm{~m}$. Additionally, variable fluorescence was measured at $12 \mathrm{~m}$, and chlorophyll $a$ and algal spectral absorption were occasionally measured in the thermocline instead of at $15 \mathrm{~m}$. P-E parameters were measured only at 3 and $9 \mathrm{~m}$. Temperature and salinity profiles were recorded with an Aquapack CTDF (Chelsea Instruments). The depth of the homogeneous surface mixed layer $\left(z_{\mathrm{SML}}\right)$ was determined as $\delta\left(z_{\mathrm{SML}}\right)-\delta$ (surface) $\geq 0.1 \mathrm{~kg} \mathrm{~m}^{-3}$ (Keller et al. 2001), where $\delta\left(z_{\mathrm{SML}}\right)$ and $\delta$ (surface) are the densities at the lower limit of the surface mixed layer and at the surface, respectively.
Algal taxonomy and chlorophyll a. Biomass (wet weight based on plasma volumes of individual taxa, picoplankton excluded) of nano- and microphytoplankton species (including a phototrophic ciliate Mesodinium rubrum) preserved with acid Lugol's solution was determined using an inverted microscope (Utermöhl 1958). Samples of chlorophyll a (chl a) were filtered onto GF/F glass-fibre filters (Whatman), and subsequently extracted with $96 \%$ ethanol for $24 \mathrm{~h}$ at room temperature (Jespersen \& Christoffersen 1987). Concentrations of $\mathrm{chl} a$ were measured with a spectrofluorometer (Shimadzu RFPC-5001) calibrated using pure chl a (Sigma).

Radiometric measurements. The underwater light profile down to $15 \mathrm{~m}$ was measured with a spherical collector (LI-192SA, Li-Cor) measuring scalar irradiance $\left(E_{0}(z)\right)$ and a cosine collector (LI-193SA, Li-Cor) measuring downward plane irradiance $\left(E_{\mathrm{d}}(z)\right)$. The downward-plane irradiance above the surface $\left(E_{\mathrm{d}}(+)\right)$ was measured during these profiles and the ${ }^{14} \mathrm{C}$-incubation periods. The euphotic depth $\left(z_{\mathrm{eu}}\right)$ was determined according to Kirk (1994):

$$
z_{\mathrm{eu}}=4.6 \times \bar{K}_{d}^{-1}
$$

where $\bar{K}_{d}$ is the average diffuse attenuation coefficient of downward-plane irradiance calculated for the layer from 1 to $10 \mathrm{~m}$. The spectral downward-plane irradiance $\left(E_{\mathrm{d}}(z, \lambda)\right)$ was measured at $2 \mathrm{~nm}$ resolution using a spectroradiometer (LI-1800, Li-Cor) equipped with a cosine collector. The spectral diffuse attenuation coefficient of downward-plane irradiance $\left(K_{d}(\lambda)\right)$ was calculated for the uppermost surface layer ( 3 or $5 \mathrm{~m}$ ), and the in situ light field was extrapolated down to $15 \mathrm{~m}$ assuming unvarying $K_{d}(\lambda)$. The spectral measurements were carried out on 5 days at different times of the seasonal phytoplankton succession (see Fig. 2). For the

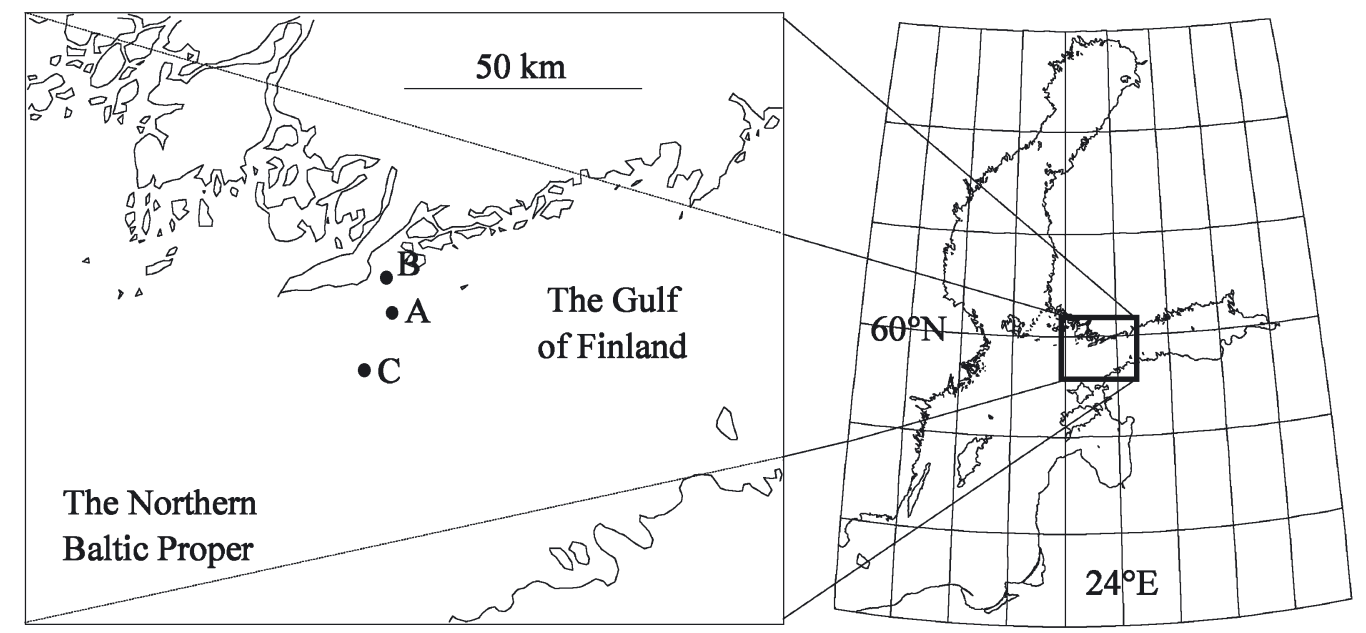

Fig. 1. (A) Study site, (B) Stn 11 in the vicinity of island of Långskär, and (C) station at which measurements were carried out in 1999 
whole study period, the downward-plane irradiance $\left(E_{\mathrm{d}}(d)\right)$ was collected with a half-spherical collector and logged once per minute at the Helsinki-Vantaa airport meteorological station $\left(60^{\circ} 19^{\prime} \mathrm{N}, 24^{\circ} 58^{\prime} \mathrm{E}\right)$.

In vivo spectral measurements. The optical density (from 380 to $800 \mathrm{~nm}$ ) of total particulate matter collected on GF/F filters (Whatman) was measured using the filter-pad technique with a dual beam spectrophotometer (Shimadzu 2101-UVPC) (Yentsch 1962). The absorption coefficient for particulate matter $\left(a_{\mathrm{p}}(\lambda)\right)$ was calculated using equations and a pathlength amplification algorithm provided by Cleveland \& Weidemann (1993). The $a_{\mathrm{p}}(\lambda)$ obtained was decomposed into the absorption coefficient due to phytoplankton $\left(a_{\mathrm{ph}}(\lambda)\right)$ and tripton using the algorithm of Bricaud \& Stramski (1990) modified by Seppälä et al. (2003).

The absorption coefficient of photosynthetic pigments $\left(a_{\mathrm{ps}}(\lambda)\right)$ was estimated from the quantum-corrected and scaled far-red excitation spectra of phytoplankton (Neori et al. 1988). In vivo fluorescence excitation spectra (excitation from 380 to $700 \mathrm{~nm}$, emission $730 \mathrm{~nm})$ were measured on a (3-[3,4-dichlorophenyl]1,1-dimethylurea) (DCMU)-treated (final concentration $20 \mu \mathrm{M}$ ) suspension using a spectrofluorometer (Shimadzu RFPC-5001). The fluorescence measured from a $0.4 \mu \mathrm{m}$-filtered sample was subtracted from all spectra to compensate for Raman scattering and CDOM (chromophoric dissolved organic matter) fluorescence. The spectra were quantum-corrected for the instrument optics so that they are comparable with the absorption spectra (see Kopf \& Heinze 1984). Scaling of excitation spectra was carried out so that no overshoot occurred relative to $a_{\mathrm{ph}}(\lambda)$ in the wavelength interval 500 to $690 \mathrm{~nm}$ (Johnsen \& Sakshaug 1996).

Chl $a$-specific absorption for phytoplankton $\left(a_{\mathrm{ph}}{ }^{*}(\lambda)\right)$ and photosynthetic pigments $\left(a_{\mathrm{ps}}{ }^{*}(\lambda)\right)$ were obtained by normalising the corresponding absorption coefficients to chl a concentrations. The difference spectra between $a_{\mathrm{ph}}{ }^{*}(\lambda)$ and $a_{\mathrm{ps}}{ }^{*}(\lambda)$ estimate the absorption by photoprotective pigments. Furthermore, the spectrally-weighted absorption coefficients $\left(\bar{a}_{x}{ }^{*}\right)$ were calculated as:

$$
\bar{a}_{X}{ }^{*}=\sum_{400}^{700}\left[E_{\mathrm{d}}(z, \lambda) \times a_{X}{ }^{*}(z, \lambda)\right] \times\left[\sum_{400}^{700} E_{\mathrm{d}}(z, \lambda)\right]^{-1}
$$

where subscript $x$ is either ph (the absorption of all pigments) or ps (photosynthetic pigments only).

Primary production. The apparent net assimilation of carbon was determined as a ${ }^{14} \mathrm{C}-\mathrm{CO}_{2}$ uptake according to the method of Steemann Nielsen (1952) as modified by Niemi et al. (1983). Activities from 3.4 to $5.4 \mu \mathrm{Ci}$ were added to $50 \mathrm{ml}$ samples in the form of a $\mathrm{NaHCO}_{3}$ aqueous solution $\left({ }^{14} \mathrm{C}\right.$ Agency, Denmark). The incubations (80 to $115 \mathrm{~min}$ ) at $0,3,6,9$, and $15 \mathrm{~m}$ were started within 10 min of sampling. Radioactivity was measured with a 1217 Rackbeta liquid scintillation counter (LKB Wallac, Finland). The amount of total inorganic carbon was analysed using a Unicarbo carbon analyser (Elektro Dynamo, Finland). Because of the relatively short incubation periods, ${ }^{14} \mathrm{C}$-based in situ primary productivity $\left(P_{M 1}\right)$ was presumed to refer to gross $\mathrm{C}$ uptake rate as defined by Sakshaug et al. (1997).

P-E measurements. P-E parameters were measured in 12 steps from 0 to $310 \mu \mathrm{mol} \mathrm{q} \mathrm{m}{ }^{-2} \mathrm{~s}^{-1}$ using a P-E incubator (Hydrobios) equipped with 10 Osram L8W/20 cool-white fluorescent tubes. The incubations (90 to $120 \mathrm{~min}$ ) were started within $3 \mathrm{~h}$ of sampling. As no photoinhibition was apparent, the model of Webb et al. (1974) was fitted to the data to retrieve the maximum light-utilisation coefficient $(\alpha)$ and the light-saturated photosynthetic rate $\left(P_{\max }\right)$. For a total of 6 stationdays, $P_{\max }$ was not satisfyingly modelled, and the excluded $P_{\max }$ values were replaced by values obtained using the function of in situ temperature $\left(P_{\max }=-0.011 \times\right.$ temperature ${ }^{2}+0.33 \times$ temperature + $\left.1.46, r^{2}=0.71, \mathrm{n}=14\right)$. We recognize the fact that temperature serves only as a proxy for the factors directly influencing $P_{\max }$ (Behrenfeld et al. 2002).

The maximum quantum yield for $\mathrm{C}$ fixation $\left(\phi_{\max }^{\mathrm{x}}\right)$ was calculated as based on the absorption by all pigments, or by photosynthetic pigments only (Sakshaug et al. 1991):

$$
\phi_{\max }^{x}=\alpha \times\left(\bar{a}_{x}^{*}\right)^{-1}
$$

where super-/subscript $x$ is either ph (all pigments) or ps (photosynthetic pigments only).

Measurements of variable fluorescence. Variable fluorescence transients were measured using a FAST ${ }^{\text {tracka }}$ FRR fluorometer (Chelsea Instruments). Calibration of the baseline, scatter, and reference function were carried out according to the manufacturer's instructions. The excitation spectrum (Fig. 2) of the light source of the FAST tracka (an array of Nichia NSPB300A LEDs with a BG39 filter) was provided by J. Atkins, Chelsea Instruments.

FRRF measurements were carried out in situ by deploying the FAST ${ }^{\text {tracka }}$ using a stern-mounted crane. The FAST ${ }^{\text {tracka }}$ was mounted onto a protective frame with external photosynthetically active ratiation (PAR) and pressure sensors (Chelsea Instruments). The fluorescence parameters $F_{\mathrm{o}}, F_{\mathrm{m}}, F_{1} F_{\mathrm{m}}^{\prime} \phi^{\prime}, \sigma_{\mathrm{PSII}}$, and $p^{\prime}$ (see Table 1) were derived from the raw fluorescence data using v5LITE software, based on the equations of Kolber et al. (1998), and developed by S. Laney. The full unconstrained iterative model (involving $F_{,} F^{\prime}{ }_{m}, \sigma_{\text {PSII }}{ }^{\prime}$, and $p^{\prime}$ ) was used as a default. If the requirement $0<p^{\prime}$ $<0.6$ ( $p^{\prime}<0$ is physiologically impossible) was not met in at least 3 replicate measurements of a total of 5 , a reduced model (involving $F_{,} F_{\mathrm{m}}^{\prime}, \sigma_{\mathrm{PSII}}$ ) was adopted. It is obvious that $\sigma_{\mathrm{PSII}}$ is underestimated by neglecting 


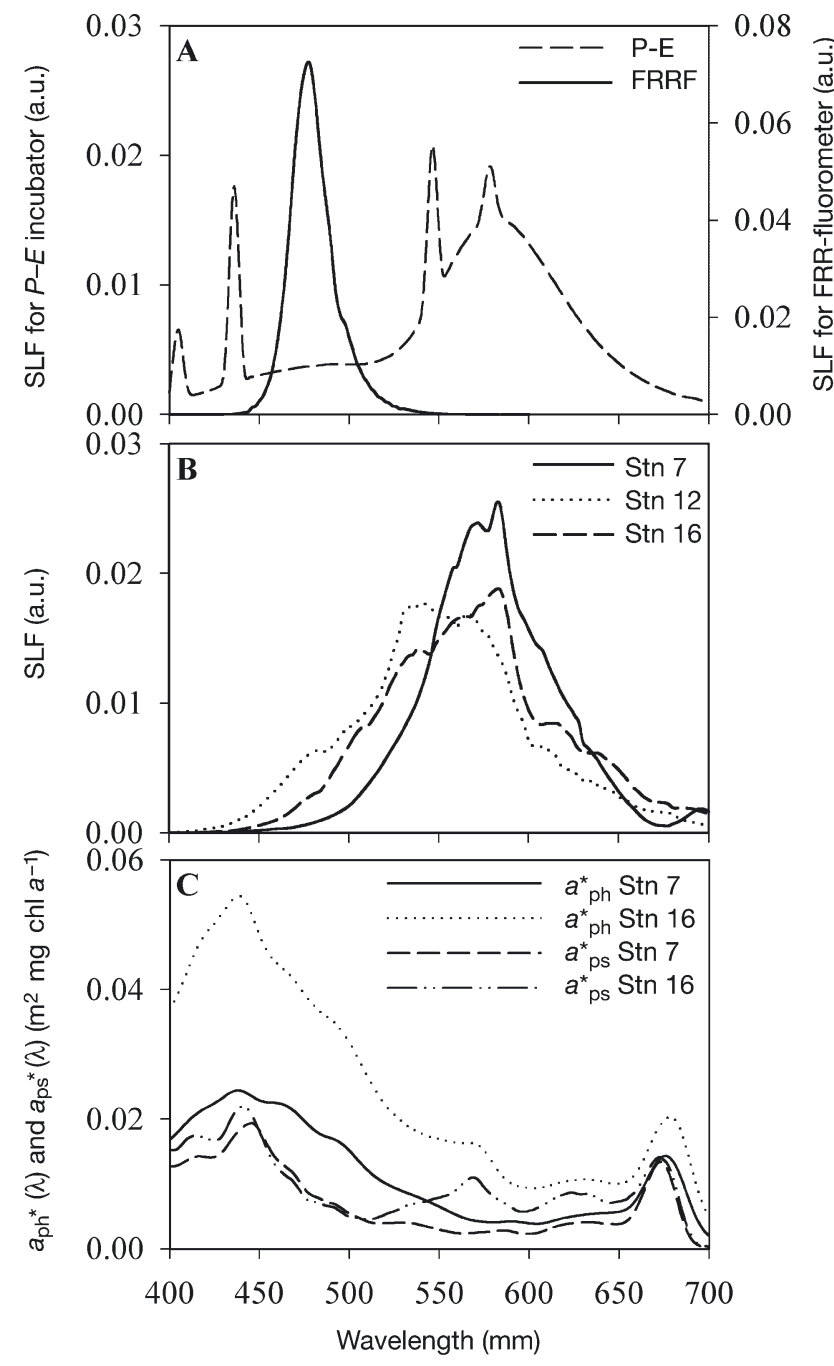

Fig. 2. (A) Excitation spectra of instruments used; (B) spectral light field at $6 \mathrm{~m}$ on 3 of a total of 5 station-days on which spectral light flux (SLF) was measured during study at Stns 7, 12 , and $16 ;(C)$ algal spectral absorption characteristics, showing $a_{\mathrm{ph}}{ }^{*}(\lambda)$ and $a_{\mathrm{ps}}{ }^{*}(\lambda)$ at Stns 7 and 16. Spectra in upper and middle graphs scaled so that integrated area equals unity. Here and in subsequent figures, abbreviations as in Table 1

$p^{\prime}$, as noted by Kolber et al. (1998). When the whole dataset was run with both the full model and the reduced model, neglecting $p^{\prime}$ caused $\sigma_{\text {PSII }}$ to decrease on average by $\sim 11 \%$.

The correct determination of the photochemical quenching $\left(q_{\mathrm{p}}\right)$ requires a knowledge of $F^{\prime}$ o (see Table 1):

$$
q_{\mathrm{p}}=\left(F_{\mathrm{m}}^{\prime}-F\right) \times\left(F_{\mathrm{m}}^{\prime}-F_{\mathrm{o}}^{\prime}\right)^{-1}
$$

As the non-photochemical quenching $\left(q_{\mathrm{n}}\right)$ remains constant only during a small time window after placing the sample into darkness (Oxborough \& Baker 1997), the exact evaluation of $F^{\prime}$ o would have required an almost instantaneous FRRF measurement after reaching a new sampling depth. This was practically impossible, and $q_{\mathrm{p}}$ was affected by the decay of the fast components of $q_{\mathrm{n}}$ (Krause \& Weis 1991). $F^{\prime}{ }_{\mathrm{o}}$ and $q_{\mathrm{p}}$ were therefore recalculated using equations involving $F_{\mathrm{o}}$ (Oxborough \& Baker 1997).

Spectral corrections. The photoadaptive variables $\alpha$ and $\sigma_{\text {PSII }}$ ' were scaled to the in situ light field by modifying the procedure applied by Suggett et al. (2001). The spectral scaling was based on the absorption for photosynthetic pigments. As the light spectra of the P-E incubator and the FRR fluorometer differed from the in situ light field, a spectral scaling was carried out by calculating the effective photosynthetic absorption coefficients $\left(\bar{a}_{X}\right)$ for each light regime:

$\bar{a}_{X}(z)=\sum_{400}^{700}\left[E_{X}(z, \lambda) \times a_{\mathrm{ps}}^{*}(z, \lambda)\right] \times\left[\sum_{400}^{700} E_{X}(z, \lambda)\right]^{-1}$

where subscript $x$ is either in vivo (the in situ light field) FRRF or P-E. $E_{\text {in vivo }}(z, \lambda)$ is also denoted $E_{\mathrm{d}}(z, \lambda)$. The parameters $E_{\mathrm{FRRF}}(\lambda)$ and $E_{\mathrm{P}-\mathrm{E}}(\lambda)$ represent the excitations created by the array of LEDs of the FAST ${ }^{\text {tracka }}$ and the light source of the P-E incubator, respectively, and have no depth-dependence. For the comparison of the light sources, the total quantum fluxes from 400 to $700 \mathrm{~nm}$ were scaled to unity. A scaling factor $(D)$ evaluates how much more $(D>1)$ or less $(D<1)$ effectively photosynthetic pigments absorb light in the treatments compared to in situ conditions in the water column:

$$
D_{X}(z)=\bar{a}_{X} \times \bar{a}_{\text {in vivo }}(z)^{-1}
$$

where subscript $x$ is either FRRF or P-E. The resulting values of $D_{\text {FRRF }}$ and $D_{\text {P-E }}$ were then used in scaling $\sigma_{\text {PSII }}{ }^{\prime}$ (the corrected $\sigma_{\mathrm{PSII}}$ ' equals the original value divided by $D_{\text {FRRF }}$ ), and in scaling the irradiance levels inside the P-E incubator for the determination of $\alpha$ (corrected irradiance levels equal the original levels multiplied by $D_{\text {P-E }}$ ), respectively.

Primary productivity models. Primary production was estimated based either solely on the in situ ${ }^{14} \mathrm{C}$ incubations (Model 1, referred as ' $\mathrm{M} 1$ '), or on the biooptical parameters (P-E parameters in 'M2', P-E and FRRF parameters in 'M3', FRRF parameters in 'M4'). All primary productivity estimates $\left(\mathrm{P}_{\mathrm{M} 1}, \mathrm{P}_{\mathrm{M} 2}, \mathrm{P}_{\mathrm{M} 3}\right.$, and $\mathrm{P}_{\mathrm{M} 4}$ ) obtained with the models are in units of $\mathrm{mg} \mathrm{C} \mathrm{m}^{-3}$ $\mathrm{h}^{-1} . \mathrm{P}_{\mathrm{M} 2}, \mathrm{P}_{\mathrm{M} 3}$, and $\mathrm{P}_{\mathrm{M} 4}$ were calculated using the spectrally-scaled $\alpha$ and $\sigma_{\text {PSII }}$ that had been converted to match the natural light field. Furthermore, the light regime used in M2, M3 and M4 equals the average $E_{\mathrm{o}}(z)$ of the ${ }^{14} \mathrm{C}$-incubation period.

M2 and M3 differ from each other in how the conversion efficiency of light into chemical energy is defined. In M2, it was formulated against the absorption of the incident light by all pigments, adopting the model of Webb et al. (1974): 
Table 1. Definitions and units of parameters used in present study. a.u.: arbitrary units; PAR: photosynthetically active radiation; PS II:Photosystem II; RC: reaction centre; q: quanta; $\mathrm{e}^{-}$: electron

\begin{tabular}{|c|c|}
\hline Unit & Definition \\
\hline VABP & Vernal algal bloom period, Stns 3 to 7 \\
\hline LSBP & Late-summer bloom period, Stns 13 to 17 \\
\hline$z_{\mathrm{eu}}$ & Euphotic depth (m) \\
\hline$z_{\mathrm{SML}}$ & Depth of surface mixed layer $(\mathrm{m})$ \\
\hline$E_{0}(z)$ & Scalar irradiance (PAR, 400 to $\left.700 \mathrm{~nm}, \mu \mathrm{mol} \mathrm{q} \mathrm{m} \mathrm{m}^{-2} \mathrm{~s}^{-1}\right)$ \\
\hline$E_{\mathrm{d}}(z)$ & 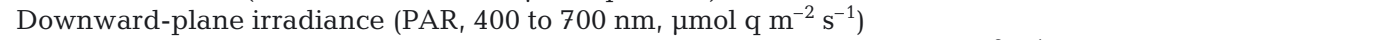 \\
\hline$E_{\mathrm{d}}(+)$ & 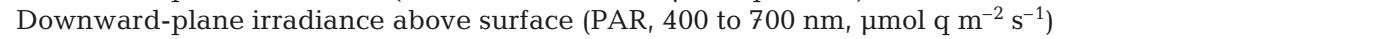 \\
\hline$E_{\mathrm{d}}(\mathrm{z}, \lambda)$ & 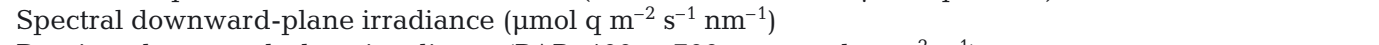 \\
\hline$E_{\mathrm{d}}(d)$ & 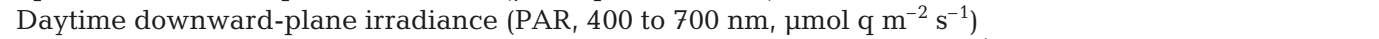 \\
\hline$K_{d}$ & Average diffuse attenuation coefficient of downward-plane irradiance $\left(\mathrm{m}^{-1}\right)$ \\
\hline$K_{d}(\lambda)$ & Spectral diffuse attenuation coefficient of downward-plane irradiance $\left(\mathrm{m}^{-1} \mathrm{~nm}^{-1}\right)$ \\
\hline$a_{\mathrm{ph}}(\lambda), a_{\mathrm{ps}}(\lambda)$ & Absorption coefficient of phytoplankton, and of photosynthetic pigments (range 400 to $700 \mathrm{~nm}, \mathrm{~m}^{-1}$ ) \\
\hline$a_{\mathrm{ph}}^{*}(\lambda), a_{\mathrm{ps}}^{*}(\lambda)$ & $\begin{array}{l}\text { Chl a-specific absorption by phytoplankton, and by photosynthetic pigments (range } 400 \text { to } 700 \mathrm{~nm} \text {, } \\
\mathrm{m}^{2} \mathrm{mg} \mathrm{chl} \mathrm{a}^{-1} \text { ) }\end{array}$ \\
\hline$\overline{\mathrm{a}}_{\mathrm{ph}}{ }^{*}, \overline{\mathrm{a}}_{\mathrm{ps}}{ }^{*}$ & $\begin{array}{l}\text { Chl } a \text {-specific, wavelength-dependent absorption by all pigmentation, and by the photosynthetic } \\
\text { pigments (range } 400 \text { to } 700 \mathrm{~nm}, \mathrm{~m}^{2} \mathrm{mg} \mathrm{chl} \mathrm{a}^{-1} \text { ) }\end{array}$ \\
\hline $\bar{a}_{\text {in vivor }} \bar{a}_{\mathrm{FRRF}}, \overline{\mathrm{a}}_{P-E}$ & $\begin{array}{l}\text { Effective light absorption by photosynthetic pigments in situ in the water column, in the vicinity of } \\
\text { optical windows of FRR fluorometer, or inside the P-E incubator (a.u.) }\end{array}$ \\
\hline$D_{\text {FRRF }}, D_{P-E}$ & Spectral scaling factors for $\sigma_{\text {PSII }}$ and $\alpha$ (a.u.) \\
\hline M1, M2, M3, M4 & Primary productivity models used. See 'Materials and methods' for details \\
\hline $\mathrm{P}_{\mathrm{M} 1}$ & ${ }^{14} \mathrm{C}$-based in situ primary productivity $\left(\mathrm{mg} \mathrm{C} \mathrm{m}^{-3} \mathrm{~h}^{-1}\right)$ \\
\hline $\mathrm{P}_{\mathrm{M} 2}, \mathrm{P}_{\mathrm{M} 3}, \mathrm{P}_{\mathrm{M} 4}$ & Primary productivity obtained by bio-optical models $\mathrm{M} 2$, M3, and M4 (mg C m${ }^{-3} \mathrm{~h}^{-1}$ ) \\
\hline $\mathrm{P}_{\mathrm{eu}}$ & Productivity over euphotic zone $\left(\mathrm{mg} \mathrm{C}^{-2} \mathrm{~h}^{-1}\right)$ \\
\hline$\alpha$ & 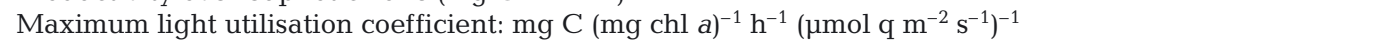 \\
\hline$P_{\max }$ & Light-saturated photosynthetic rate: $\mathrm{mg} \mathrm{C}(\mathrm{mg} \mathrm{chl} a)^{-1} \mathrm{~h}^{-1}$ \\
\hline$E_{\mathrm{k}}$ & Light saturation parameter $\left(\mu \mathrm{mol} \mathrm{q} \mathrm{m}^{-2} \mathrm{~s}^{-1}\right)$ \\
\hline$\phi_{\max }^{\mathrm{ph}}, \phi_{\max }^{\mathrm{ps}}$ & $\begin{array}{l}\text { Maximum quantum yield for } \mathrm{C} \text { fixation, mol C }(\mathrm{mol} \mathrm{q})^{-1} \text {, based on absorption of the total pigmentation } \\
\text { or on absorption of photosynthetic pigments }\end{array}$ \\
\hline DPP & Daily primary production $\left(\mathrm{mg} \mathrm{C} \mathrm{m} \mathrm{m}^{-2} \mathrm{~d}^{-1}\right)$ \\
\hline SPP & Seasonal primary production $\left(\mathrm{g} \mathrm{C} \mathrm{m}^{-2} \mathrm{yr}^{-1}\right)$ \\
\hline$F_{\mathrm{o}}, F_{\mathrm{m}}$ & $\begin{array}{l}\text { Initial and maximal in vivo fluorescence yield in dark-adapted state in absence of non-photochemical } \\
\text { quenching }\end{array}$ \\
\hline$F_{1} F_{\mathrm{m}}^{\prime}$ & $\begin{array}{l}\text { Initial and maximal in vivo fluorescence yield at ambient irradiance in presence of non-photochemical } \\
\text { quenching }\end{array}$ \\
\hline$F^{\prime}{ }_{0}$ & In vivo fluorescence yield at ambient irradiance, subsequently measured after 1 to $2 \mathrm{~s}$ of dark adaptation \\
\hline$\phi, \phi^{\prime}$ & Maximal and functional photochemical energy conversion efficiency, $\phi=\left(F_{\mathrm{m}}-F_{\mathrm{o}}\right) / F_{\mathrm{m}}, \phi^{\prime}=\left(F_{\mathrm{m}}^{\prime}-F\right) / F_{\mathrm{m}}^{\prime}$ \\
\hline$f, f^{\prime}$ & Proportion of functional RCs in PSII in dark-adapted state and at the ambient irradiance \\
\hline$\sigma_{\mathrm{PSII}}, \sigma_{\mathrm{PSII}}$ & Functional absorption cross-section of PSII in dark-adapted state and at ambient irradiance $\left(\AA^{2} \mathrm{q}^{-1}\right)$ \\
\hline$q_{\mathrm{p}}$ & Photochemical quenching \\
\hline$q_{\mathrm{n}}$ & Non-photochemical quenching \\
\hline$\phi_{\mathrm{c}}$ & Quantum yield of electron transport: $\mathrm{mol} \mathrm{O}_{2}\left(\mathrm{~mol} \mathrm{e}^{-}\right)^{-1}$ \\
\hline$\phi_{\mathrm{rc}}$ & 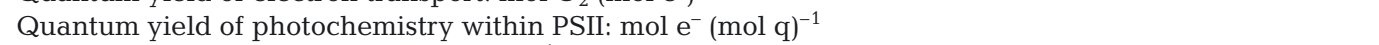 \\
\hline$P Q$ & Photosynthetic quotient: $\mathrm{mol} \mathrm{O}_{2}(\mathrm{~mol} \mathrm{C})^{-1}$ \\
\hline$p, p^{\prime}$ & Extent of energy transfer between RCIIs in dark-adapted state and at ambient irradiance \\
\hline$n_{\text {PSII }}$ & Ratio of RCII to total PSII chl a pigments: $\mathrm{mol} \mathrm{e}^{-}(\mathrm{mol} \mathrm{chl} a)^{-1}$ \\
\hline
\end{tabular}

$$
\mathrm{M} 2: \mathrm{P}_{\mathrm{M} 2}=P_{\max } \times\left(1-\mathrm{e}^{-\alpha \times E_{0}(z) / P_{\max }}\right) \times \operatorname{chl} a
$$

In M3, the conversion efficiency of light was calculated against the light absorbed by the photosynthetic pigments. The product of $E_{\mathrm{o}}(z)$ and $\sigma_{\mathrm{PSII}}$, the excitation delivery to reaction centre II (RCII), was scaled per chl a molecule by the ratio of RCII to total PSII chl a pigments $\left(n_{\text {PSII }}\right)$. As reliable $n_{\text {PSII }}$ values from natural phytoplankton communities are scarce, the fixed value of $1 / 500 \mathrm{~mol} \mathrm{e}^{-}(\mathrm{mol} \mathrm{chl} \mathrm{a})^{-1}$ was used, where $\mathrm{e}^{-}=$electron (Falkowski \& Kolber 1995):

$$
\mathrm{M} 3: \mathrm{P}_{\mathrm{M} 3}=E_{\mathrm{o}}(z) \times \sigma_{\mathrm{PSII}}{ }^{\prime} \times \phi_{\max }^{\mathrm{ps}} \times n_{\mathrm{PSII}} \times \mathrm{chl} a
$$

In principle, the P-E based $\phi_{\max }$ agrees with the actual in situ value at depths where PP is light-limited (Vaillancourt et al. 2003). As the phytoplankton community was most probably light-limited at $9 \mathrm{~m}$ (the irradiance was, on seasonal average, $3.0 \%$ of the value just below the surface), and probably not lightsaturated (near $E_{k}$ ) at $3 \mathrm{~m}$ (corresponding value $24 \%$ ), P-E based $\phi_{\max }^{\mathrm{ps}}$ values were used in M3 without conversions. M4 utilises equations modified from Fal- 
kowski \& Raven (1997). The quantum yield of electron transport $\left(\phi_{c}\right)$ was fixed as $0.18 \mathrm{~mol} \mathrm{O}_{2}\left(\mathrm{~mol} \mathrm{e}^{-}\right)^{-1}$ (Flameling \& Kronkamp 1998). The photosynthetic quotient $(P Q)$ was fixed as $1.5 \mathrm{~mol} \mathrm{O}_{2}(\mathrm{~mol} \mathrm{C})^{-1}$, an annual average value in the vicinity of the study area (Kuparinen 1985). The quantum yield of photochemistry within PSII $\left(\phi_{\mathrm{rc}}\right)$ was assumed to be unity:

$$
\begin{aligned}
\mathrm{M} 4: \mathrm{P}_{\mathrm{M} 4}= & E_{\mathrm{o}}(z) \times \sigma_{\mathrm{PSII}}{ }^{\prime} \times f^{\prime} \times q_{\mathrm{p}} \times \phi_{\mathrm{rc}} \times \phi_{\mathrm{c}} \times \\
& P Q^{-1} \times n_{\mathrm{PSII}} \times \mathrm{chl} a
\end{aligned}
$$

Areal primary production. Seasonal primary production (SPP) in the euphotic zone based on M1 was evaluated in 5 stages: (1) The productivity of the euphotic zone was calculated from depthwise values of $\mathrm{P}_{\mathrm{M} 1}$ by integration over depth to $z_{\mathrm{eu}}$. (2) To calculate daily primary production (DPP), the time-dependent variation in solar irradiance was taken into account by scaling the productivity of the euphotic zone with a ratio of cumulative light flux of the daytime to that of the ${ }^{14} \mathrm{C}$ incubation period. The fraction of the solar irradiance reflected from the sea surface, which is dependent on the angle of the sun and varies during the daytime, was not included in the models. The length of the day was restricted to the time period when $E_{\mathrm{d}}(d)$ was $>5 \mu \mathrm{mol}$ $q \mathrm{~m}^{-2} \mathrm{~s}^{-1}$. (3) As $\mathrm{P}_{\mathrm{M} 1}$ was presumed to represent gross $C$ uptake rates, respiration $(R)$ was subtracted from it as a fixed fraction. As the ratio of $R$ to PP of the plankton community is largely regulated by seasonal changes in the size structure of the community (Smith \& Kemp 2001), the size structure of the community was used as a criterion for dividing the study period into spring and summer periods; the division was set between Stn 11 and Stn 12. Between these 2 study days, the proportion of picoplankton increased by $18 \%$, while microplankton decreased by $15 \%$ in biomass (as estimated by chl a) in the upper $15 \mathrm{~m}$. Simultaneously, a marked progress in summer stratification occurred (Fig. 3). $R$ was assumed to consume 18 and $42 \%$ of the gross phytoplankton production during the spring and summer periods, respectively (Kuparinen 1984, 1987, Kuparinen et al. 1984). (4) DPP was determined using only 1 set of measurements between 9:30 and 11:00 h local time, i.e. probably near the daily peak of algal photosynthetic activity. Thus, diurnal variability in algal photosynthetic performance had to be taken into consideration to avoid overestimates of DPP (Harding et al. 1981). This was done using the diurnality of $\alpha$, employing the results of Harding et al. (1981, 1983), and Smith et al. (1989). According to their results, DPP would be overestimated by $16 \%$, so the values were corrected accordingly. The general formula for the determination of DPP with M1 is as follows:

$\mathrm{DPP}=\left[\left(\sum_{\text {sunrise }}^{\text {sunset }} E_{\mathrm{d}}(d)\right) \times\left(\sum_{\text {start of in situ incubation }}^{\text {end of in situ incubation }} E_{\mathrm{d}}(+)\right)^{-1}\right] \times \int_{0}^{z_{\text {eu }}}\left[\mathrm{P}_{\mathrm{M} 1}-R\right]$
(5) SPP was obtained from daily values by integration over time. It thus refers to the integrated productivity over the time period from Stns 1 to 22, and does not strictly represent the actual areal primary production of the entire growth season.

Bio-optical SPP was applied over Stages (1) to (5), except that the factor $60 / T$ was used as a multiplier in Eq. (10), where $T$ is the duration of in situ incubation in min. The values of $\alpha$ at 3 and $9 \mathrm{~m}$ were also used as a basis for the values at $0,6,12$, and $15 \mathrm{~m}$. Moreover, in order to compensate for the substantial disturbance caused by the ambient red light, the FRRF sample at $0 \mathrm{~m}$ had to be replaced by the value at $2 \mathrm{~m}$ on 6 occasions, and by the value at $3 \mathrm{~m}$ on another 6 occasions.

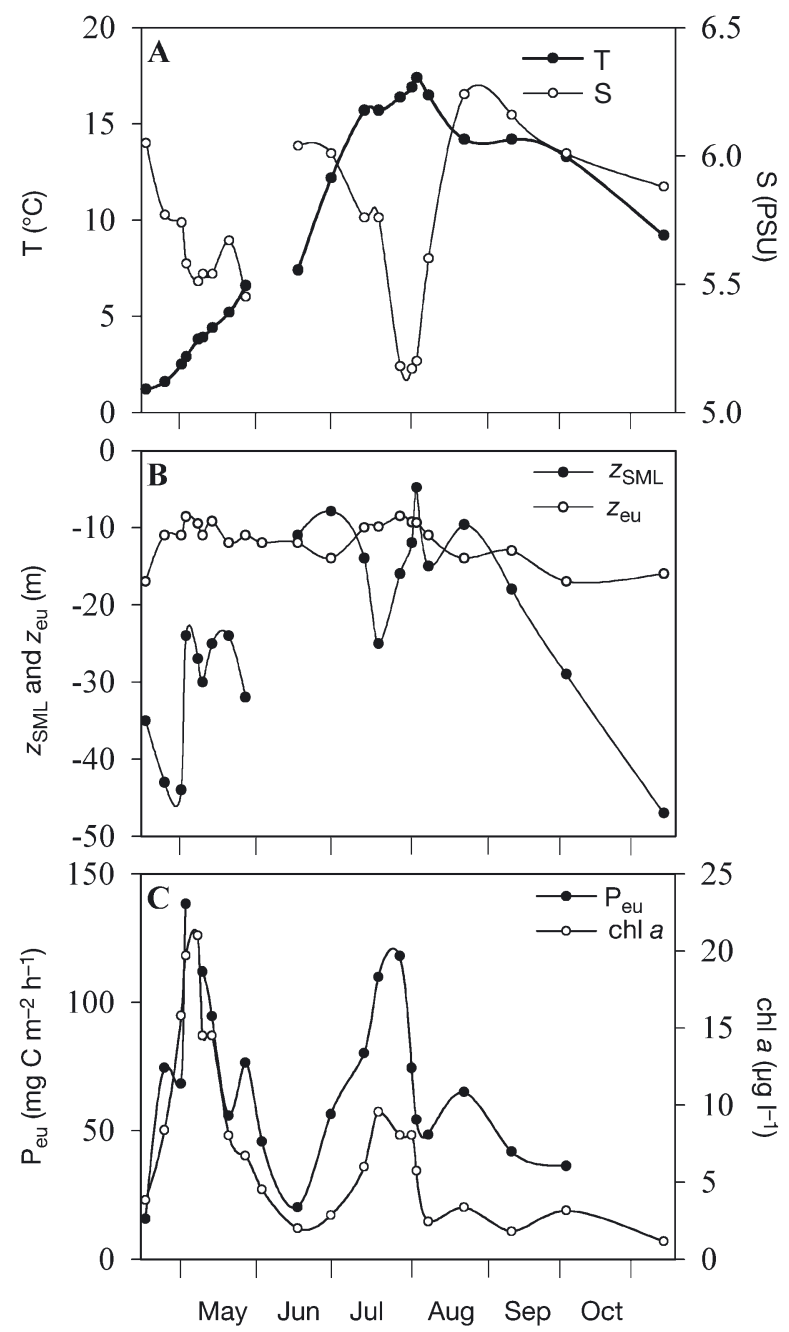

Fig. 3. (A) Temperature (T) and salinity (S); (B) depths of surface mixed layer $\left(z_{\mathrm{SML}}\right)$ and euphotic layer $\left(z_{\text {eu }}\right) ;(\mathrm{C})$ productivity in euphotic zone $\left(\mathrm{P}_{\mathrm{eu}}\right)$ and chl $a$ in growth season 2000. Temperature, salinity, and chl a are averages of measurements at 3 and $9 \mathrm{~m}$ 


\section{RESULTS}

\section{Growth season}

Phytoplankton succession followed the normal annual development in the northern Baltic Sea. The spring bloom, which was dominated by cold-water diatoms and dinoflagellates, mainly Peridiniella catenata (Dinophyceae), and Thalassiosira baltica (Bacillariophyceae), lasted for a little longer than 1 mo (Fig. 4). The peak of the vernal algal bloom period (VABP, Table 2), with chl a levels up to $21 \mathrm{\mu g} \mathrm{l}^{-1}$, occurred in a deeply-mixed water column during Stns 3 to 7 (Fig. 3).

After the spring bloom, the algal biomass was very low for some weeks with a significant fraction of biomass in the picoplankton (J. Seppälä \& M. Raateoja unpubl.). The late-summer phytoplankton maximum, with chl a levels up to $10 \mu \mathrm{g} \mathrm{l}^{-1}$, referred to as the late-summer bloom period (LSBP, Table 2), took place during Stns 13 to 17. Especially Aphanizomenon flosaquae (Cyanophyceae) was abundant during the LSBP (Fig. 4: Stns 13 to 17). Motile warm-water species of small cryptophytes and larger dinoflagellates, specifically the deep-water-inhabiting Heterocapsa triquetra and Dinophysis spp. (Carpenter et al. 1995, Kononen et al. 2003) were subdominant at that time. The periods of lower salinity during the VABP and LSBP were mainly caused by fresh-water runoff from the semi-enclosed inland basin nearby. The nutrient input to the study site by this runoff was not estimated, but the fresh-water input narrowed $z_{\mathrm{SML}}$ and stabilized the surface mixed layer both during spring and late summer, thereby promoting the algal blooms.

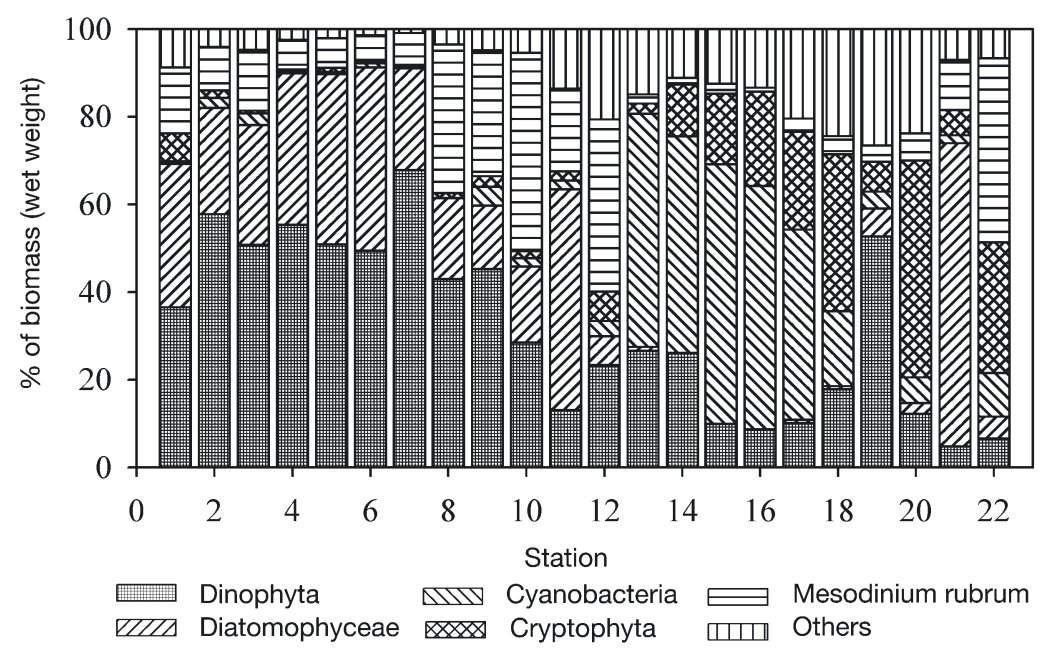

Fig. 4. Seasonally-dominant phytoplankton taxa expressed as percentages of nano-and microphytoplankton biomass in growth season 2000

\section{Light regime and bio-optical parameters}

During spring (Stn 7), at a time of relatively high light attenuation, the underwater light spectrum was biased more to the red end of the spectrum than during other seasons (Fig. 2). In contrast, during the clear-water phase in late June (Stn 12), the light regime was biased to the blue end of the spectrum. The depth of $z_{\text {eu }}$ (based on changes in PAR) varied accordingly from 8.5 to $17.2 \mathrm{~m}$, being in few cases deeper than $z_{\text {SML }}$ (Fig. 3).

Seasonal succession in the phytoplankton community structure affected $a_{\mathrm{ph}}{ }^{*}(\lambda)$ (Fig. 2). On average, $a_{\mathrm{ph}}{ }^{*}(\lambda)$ at the red peak $(677 \mathrm{~nm})$ was $0.017 \mathrm{~m}^{2} \mathrm{mg}$ $\mathrm{chl} a^{-1}$ (with a range of 0.011 to 0.022 ). As an indication of the package effect, the lowest values were observed at times of elevated phytoplankton biomass, and with generally larger phytoplankton cells, while the highest ones were found during the clear-water phase with low biomass and a dominance of picoplankton. During spring, the absorption ratio of blue-to-red light (440 to $677 \mathrm{~nm}$ ) was rather low (on the average 1.7) while in the summer this ratio increased (up to 3.0; data not shown, but see Fig. 2). This change was not only due to the package effect, but also to the photoprotective carotenoids that absorb blue and green light. Their amount was obviously low during spring, a period of low sunlight and deep mixing, and high during summer, with more sunlight and a shallower mixed layer. This difference is illustrated in Fig. $2 \mathrm{C}$ as the difference between $a_{\mathrm{ph}}{ }^{*}(\lambda)$ and $a_{\mathrm{ps}}{ }^{*}(\lambda)$. Additionally, in summer this ratio showed vertical variability, with the highest values at the surface (data not shown).

When the photosynthetic pigments only $\left(a_{\mathrm{ps}}{ }^{*}(\lambda)\right)$ are considered, the blue-to-red ratio was fairly invariable (on the average 1.5, see Fig. 2). However, the shape of $a_{\mathrm{ps}}{ }^{*}(\lambda)$ varied seasonally. Phycobiliproteins, indicating the presence of cyanobacteria and cryptomonads, were especially a source of variability in the absorption in the green to orange portion of the spectrum throughout the summer.

Taking the variability in light regime and phytoplankton absorption together, the spectrally-weighted coefficients $\bar{a}_{\mathrm{ph}}{ }^{*}$ and $\bar{a}_{\mathrm{ps}}{ }^{*}$ had clear seasonal and vertical variations, with low levels during the VABP (Table 2). Both decreased towards deeper layers (Pearson's $r=-0.41$ and -0.50, Bonferroni $\mathrm{p}<0.001, \mathrm{n}=132$ ) (Fig. 5), particularly in the near-surface layer. As a seasonal average, $\bar{a}_{\mathrm{ps}}{ }^{*}$ was $\sim 46 \%$ of $\bar{a}_{\mathrm{ph}}{ }^{*}$, this difference being lowest during the biomass peaks. 
Table 2. Bio-optical parameters as averages of values at 3 and $9 \mathrm{~m}$. For parameters and units see Table 1. nd: no data

\begin{tabular}{|c|c|c|c|c|c|c|c|c|c|}
\hline Stn & Date & Period & $\overline{\mathrm{a}}_{\mathrm{ph}}{ }^{*}$ & $\bar{a}_{\mathrm{ps}}{ }^{*}$ & $\alpha$ & $\phi_{\max }^{\mathrm{ph}}$ & $\phi_{\max }^{\mathrm{ps}}$ & $\phi^{\prime}$ & $\sigma_{\mathrm{PSII}}$ \\
\hline 1 & $11 \mathrm{Apr}$ & & 0.00798 & 0.00374 & 0.00686 & 0.0199 & 0.0449 & 0.525 & 177 \\
\hline 2 & $19 \mathrm{Apr}$ & & 0.00811 & 0.00402 & 0.00611 & 0.0175 & 0.0365 & nd & nd \\
\hline 3 & $26 \mathrm{Apr}$ & VABP & 0.00517 & 0.00300 & 0.00536 & 0.0236 & 0.0410 & 0.547 & 169 \\
\hline 4 & $28 \mathrm{Apr}$ & VABP & 0.00522 & 0.00346 & 0.00511 & 0.0229 & 0.0345 & 0.510 & 152 \\
\hline 5 & 3 May & VABP & 0.00539 & 0.00319 & 0.00361 & 0.0158 & 0.0268 & nd & nd \\
\hline 6 & 5 May & VABP & 0.00568 & 0.00310 & nd & nd & nd & 0.507 & 146 \\
\hline 7 & 9 May & VABP & 0.00609 & 0.00342 & 0.00497 & 0.0187 & 0.0335 & 0.516 & 131 \\
\hline 8 & 16 May & & 0.00813 & 0.00332 & 0.00350 & 0.0096 & 0.0241 & 0.488 & 195 \\
\hline 9 & 23 May & & 0.0102 & 0.00347 & 0.00505 & 0.0111 & 0.0335 & 0.457 & 175 \\
\hline 10 & 30 May & & 0.00845 & 0.00382 & 0.00495 & 0.0136 & 0.0313 & 0.474 & 198 \\
\hline 11 & 14 Jun & & 0.0105 & 0.00404 & 0.00509 & 0.0109 & 0.0282 & 0.364 & 193 \\
\hline 12 & 28 Jun & & 0.0166 & 0.00636 & 0.00659 & 0.0093 & 0.0241 & 0.437 & 186 \\
\hline 13 & $12 \mathrm{Jul}$ & LSBP & 0.0161 & 0.00748 & 0.00777 & 0.0111 & 0.0241 & 0.473 & 251 \\
\hline 14 & $18 \mathrm{Jul}$ & LSBP & 0.0108 & 0.00623 & 0.00601 & 0.0128 & 0.0223 & 0.493 & 197 \\
\hline 15 & $27 \mathrm{Jul}$ & LSBP & 0.0147 & 0.00818 & 0.0106 & 0.0165 & 0.0297 & 0.457 & 289 \\
\hline 16 & 1 Aug & LSBP & 0.0190 & 0.00962 & 0.00786 & 0.00958 & 0.0189 & 0.456 & 298 \\
\hline 17 & 3 Aug & LSBP & 0.0171 & 0.00935 & 0.00573 & 0.00762 & 0.0142 & 0.437 & 248 \\
\hline 18 & 8 Aug & & 0.0152 & 0.00694 & 0.00683 & 0.0104 & 0.0228 & 0.395 & 192 \\
\hline 19 & 23 Aug & & 0.0142 & 0.00529 & 0.00605 & 0.0100 & 0.0265 & 0.507 & 237 \\
\hline 20 & $12 \mathrm{Sep}$ & & 0.0157 & 0.00657 & 0.00966 & 0.0143 & 0.0340 & 0.449 & 286 \\
\hline 21 & 5 Oct & & 0.0143 & 0.00575 & 0.00607 & 0.00981 & 0.0244 & 0.505 & 236 \\
\hline 22 & $15 \mathrm{Nov}$ & & 0.0109 & 0.00400 & 0.00403 & 0.00885 & 0.0247 & 0.366 & 260 \\
\hline
\end{tabular}

\section{P-E parameters and spectral scaling factors}

The average value for the maximum light-utilisation coefficient, $\alpha$, was $0.0061 \mathrm{mg} \mathrm{C}(\mathrm{mg} \mathrm{chl} \mathrm{a})^{-1} \mathrm{~h}^{-1}(\mu \mathrm{mol} \mathrm{q}$ $\left.\mathrm{m}^{-2} \mathrm{~s}^{-1}\right)^{-1}$ (Table 2). For VABP, $\alpha$ was significantly smaller than for LSBP $(0.0048$ and 0.0081 , respectively, Student's $t$-test: $\left.t_{7}=3.7, \mathrm{p}<0.01\right)$. Generally, $\alpha$ was linearly related to the spectrally-weighted lightabsorption coefficients $\bar{a}_{\mathrm{ph}}{ }^{*}$ and $\bar{a}_{\mathrm{ps}}{ }^{*}$ (Pearson's $\mathrm{r}=$ 0.63 and 0.68, Bonferroni $\mathrm{p}<0.01, \mathrm{n}=21$ ). Depthdependent variations in $\alpha$ were also evident, as values of $\alpha$ at $9 \mathrm{~m}$ were on average $~ 85 \%$ of those at $3 \mathrm{~m}$.

The maximum quantum yield of photosynthesis, based on the absorption of total pigments, $\phi_{\max }^{\mathrm{ph}}$, was on average $0.019 \mathrm{~mol} \mathrm{C}(\mathrm{mol} \mathrm{q})^{-1}$. In $\phi_{\text {max }}^{\text {ps }}$, absorption by non-photosynthetic pigments was excluded, and consequently higher values for the maximum quantum yield were obtained, with an average of $0.029 \mathrm{~mol} \mathrm{C}$ $(\mathrm{mol} \mathrm{q})^{-1}$. As the proportion of photoprotective pigments had a seasonal pattern (see above), the difference between $\phi_{\max }^{\mathrm{ph}}$ and $\phi_{\max }^{\mathrm{ps}}$ varied, being lowest during spring (Table 2).

Seasonal patterns of the scaling factors were governed by seasonal variability in the natural light regime. The strongly biased vernal light regime resulted in higher scaling factors for the VABP compared to the rest of the study period (Mann-Whitney $U$-test, $\mathrm{n}=30$ and $102, t_{\infty}=4.5$ and 6.4 for $D_{\mathrm{P} \text {-E }}$ and $D_{\text {FRRF }} \mathrm{p}<0.001$, Fig. 5). For the VABP, the average $D_{\text {P-E }}$ (for $\alpha$ ) and $D_{\text {FRRF }}$ (for $\sigma_{\text {PSII }}$ ') were 1.58 and 2.42, respectively, whereas for the rest of the study period the corresponding values were 1.28 and 1.49. The occur-

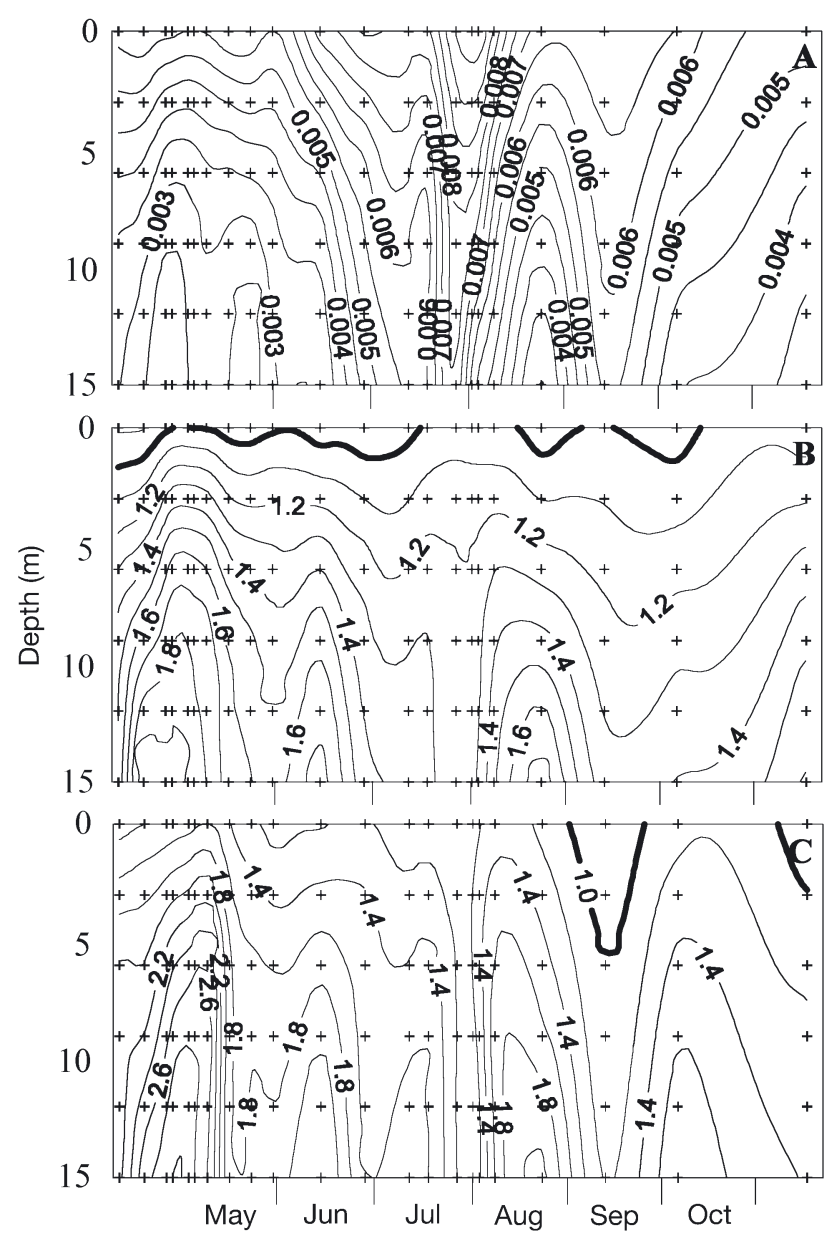

Fig. 5. Seasonal variability in (A) $\bar{a}_{\mathrm{ps}}{ }^{*}\left(\mathrm{~m}^{2} \mathrm{mg} \operatorname{chl} a^{-1}\right.$ ), (B) $D_{\text {P-Er }}$ and (C) $D_{\text {FRRF }}$ in growth season 2000 . Bold lines indicate unity 
rence of values of scaling factors above unity means that the nature of the light employed in both the FAST $^{\text {tracka }}$ and the P-E incubator made it more usable for algal photosynthesis than the in situ light. The factors increased with increasing depth; at the surface the seasonal means of $D_{\text {P-E }}$ and $D_{\text {FRRF }}$ were 0.90 and 1.13, respectively, while at $15 \mathrm{~m}$ they were 1.58 and 1.96 , respectively.

\section{Fluorescence parameters}

Ambient red light reached the detector of FAST ${ }^{\text {tracka }}$ and corrupted the fluorescence signal from 2 to $3 \mathrm{~m}$ upwards. On those station-days when $\phi^{\prime}$ was reasonably determinable in the upper $3 \mathrm{~m}$, the average value was 0.42 ( $\mathrm{SD}=0.072$ ). This value was significantly lower (Mann-Whitney $U$-test, $\mathrm{n}=17$ and 28, $t_{\infty}=2.8$, $\mathrm{p}<0.01$ ) than the average from 3 to $9 \mathrm{~m}$ on the same occasions $(0.48, \mathrm{SD}=0.057)$. Part of this difference, however, arises from the actual draw-down of the photosynthetic machinery due to supraoptimal light. Generally, noisiness in the variable fluorescence transients due to the degradation effect of ambient red light was observed to increase as an exponential function of ambient irradiance (Fig. 6).

The overall seasonal averages for $\phi^{\prime}$ and $\sigma_{\text {PSII }}$ were 0.47 and $211 \AA^{2} \mathrm{q}^{-1}$, respectively (averages of values at 3 and $9 \mathrm{~m}$, Table 2). During the VABP, the corresponding average value of $\phi^{\prime}$ was 0.52 , and thereafter this gradually decreased. The highest individual $\phi^{\prime}$ values, up to 0.58 , were observed at 6 to $12 \mathrm{~m}$ during VABP.

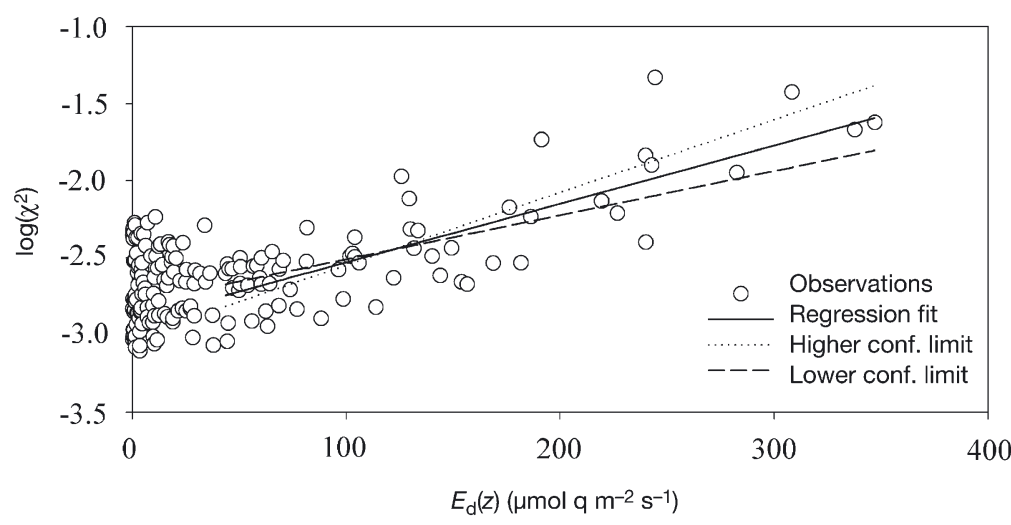

Fig. 6. Goodness of fit of iterative procedure for calculation of variable fluorescence parameters as a function of $E_{\mathrm{d}}(z)$, as described by $\chi^{2}$ statistics. Data consists of data set from present study and data set collected at entrance to Gulf of Finland in July 1999. Measuring depths were $1,3,6$, and $10 \mathrm{~m}$. Iterative procedure for both data sets was carried out with FAST tracka post-processing software FRS v.1.8. (Chelsea Instruments). Linear regression for log-transformed data (in-

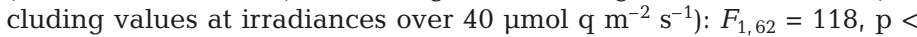
$0.001, r^{2}=0.66$; conf. limit: $99 \%$ confidence limits to regression slope

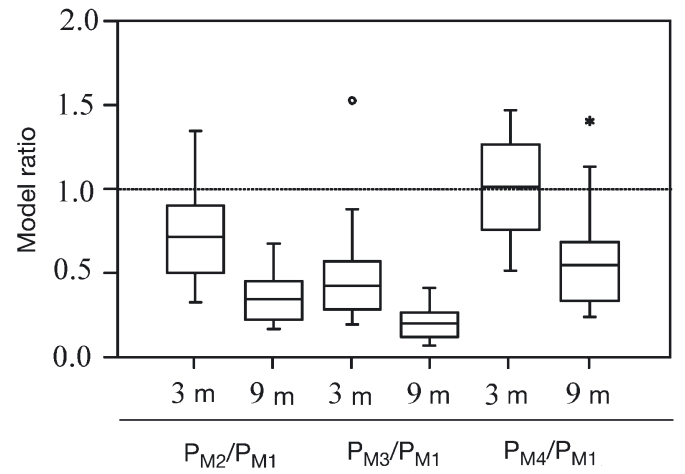

Fig. 7. Outcomes of bio-optical models M2, M3, and M4 ( $\mathrm{P}_{\mathrm{M} 2}$, $\mathrm{P}_{\mathrm{M} 3}$, and $\left.\mathrm{P}_{\mathrm{M} 4}\right)$ relative to $\mathrm{M} 1\left(\mathrm{P}_{\mathrm{M} 1}\right)$. Student's t-test between depths: $t_{17}>4.2, \mathrm{p}<0.001$ in all comparisons

$\sigma_{\text {PSII }}$ during VABP was markedly lower than during LSBP (149 and $256 \AA^{2} \mathrm{q}^{-1}$, respectively; average of values at 3 and $9 \mathrm{~m}$ ). The overall variability in $\sigma_{\text {PSII }}$ was linearly related to $\bar{a}_{\mathrm{ph}}{ }^{*}$ and $\bar{a}_{\mathrm{ps}}{ }^{*}$ (Pearson's $\mathrm{r}=0.79$ and 0.75 , Bonferroni $\mathrm{p}<0.001, \mathrm{n}=20$ ).

\section{Primary productivity models}

The models were compared at depths of 3 and $9 \mathrm{~m}$ because P-E data was available for these depths only. The bio-optical estimates $\mathrm{P}_{\mathrm{M} 2}, \mathrm{P}_{\mathrm{M} 3}$, and $\mathrm{P}_{\mathrm{M} 4}$ at 3 and $9 \mathrm{~m}$ were linearly related to $\mathrm{P}_{\mathrm{M} 1}$; the linear regression fits for the $\sqrt{ }$-transformed data as ${ }^{\mathrm{p} \text {-value }} F_{1,16} / \mathrm{r}^{2}$ were as follows $\left({ }^{*}=<0.001,{ }^{* *}=<0.01\right): 3 \mathrm{~m}={ }^{*} 56 / 0.78$, ${ }^{*} 22 / 0.58$, and ${ }^{*} 35 / 0.69 ; 9 \mathrm{~m}={ }^{*} 18 / 0.53$, ${ }^{* *} 9.1 / 0.36$, and ${ }^{* *} 9.8 / 0.38$. If the average ratios of $\mathrm{P}_{\mathrm{M} 2} / \mathrm{P}_{\mathrm{M} 3} / \mathrm{P}_{\mathrm{M} 4}$ to $\mathrm{P}_{\mathrm{M} 1}$ are calculated simply without any weighting factors based on the time periods the estimates represent, the ratios at $3 \mathrm{~m}$ were $0.73,0.49$, and 1.07 for $\mathrm{M} 2, \mathrm{M} 3$, and $\mathrm{M} 4$, respectively (Fig. 7). These ratios decreased towards deeper layers; the corresponding values at $9 \mathrm{~m}$ being only $0.32,0.18$, and 0.56. Scaling factors above unity caused the unscaled model variants to override the scaled variants as depth increased (Fig. 8). This is particularly discernible with M3 and M4 that include $\sigma_{\mathrm{PSII}}$ in their equations.

When the uppermost measured $\alpha$ (at $3 \mathrm{~m}$ ) and the FRRF parameters (from 0 to $3 \mathrm{~m}$ ) were used in $\mathrm{M} 2, \mathrm{M} 3$, and $\mathrm{M} 4$ as $0 \mathrm{~m}$ values, the abovementioned ratios of $\mathrm{P}_{\mathrm{M} 2} / \mathrm{P}_{\mathrm{M} 3} / \mathrm{P}_{\mathrm{M} 4}$ to $\mathrm{P}_{\mathrm{M} 1}$ could be estimated near the surface with reasonable accuracy. These values would be above unity for M2 and M3, and as high as 3.5 for M4. The $0 \mathrm{~m}$ samples had evidently a pronounced weight for the bio-optical PP outcomes and, 
because of this, the SPP obtained by M2 and M3 remained rather close (20 and $28 \%$ lower, see below) to $\mathrm{M} 1$, despite a tendency to underestimate M1 as the depth increased.

SPP based on $\mathrm{M} 1$ was $85.9 \mathrm{~g} \mathrm{C} \mathrm{m}^{-2} \mathrm{yr}^{-1}$. M2, M3, and M4 provided SPP estimates of 80,72 , and $166 \%$ of that of M1 (Table 3 ). As both $\alpha$ and $\sigma_{\text {PSII }}$ ' were lowered by re-scaling (see above), leaving these parameters unscaled would most strongly affect M3, which uses both these parameters ( $82 \%$ higher outcome). Like-

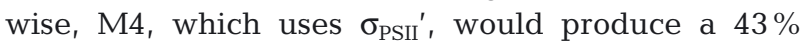
higher outcome compared to $15 \%$ for M2, which only includes $\alpha$ in its equation.
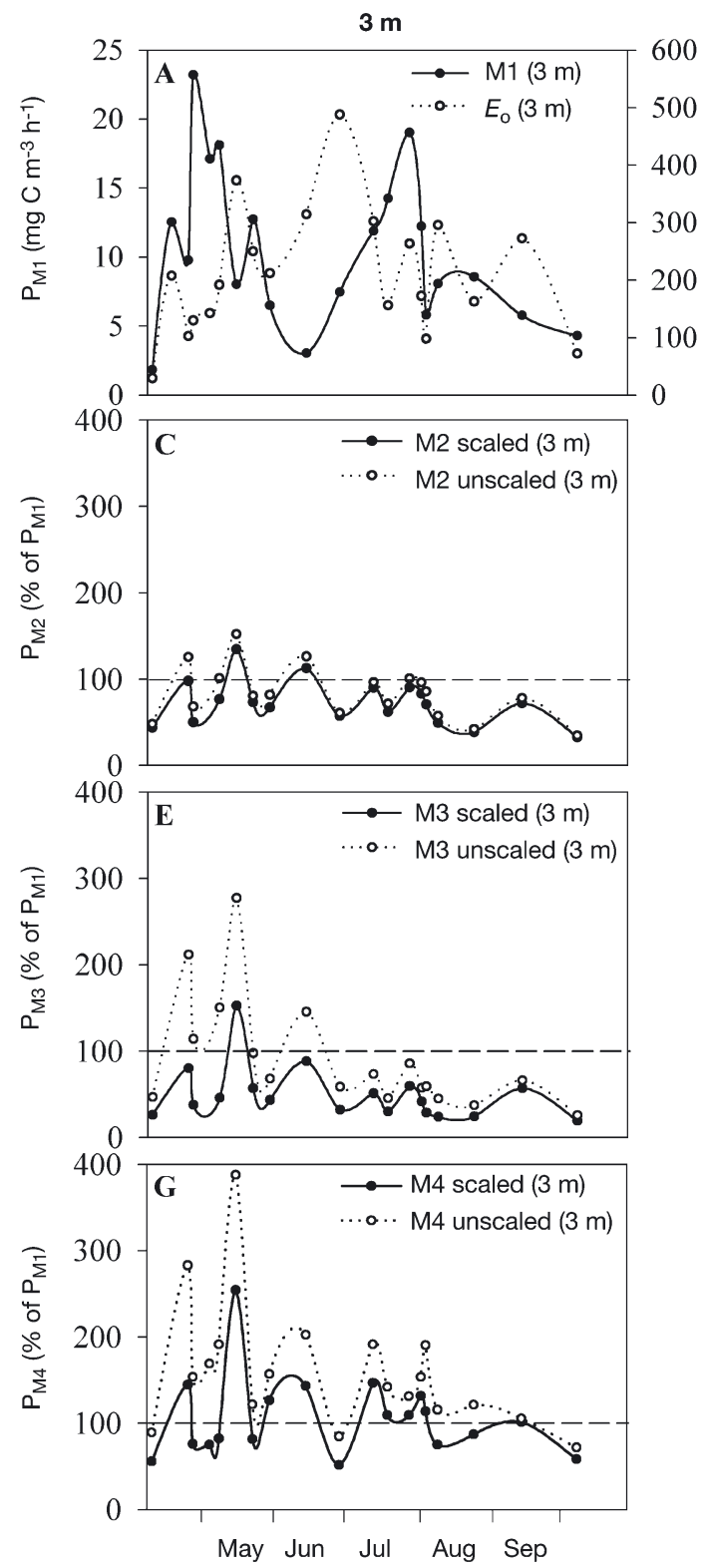

\section{DISCUSSION}

\section{Bio-optical primary productivity models}

Although coastal areas represent only a small fraction of the surface area of the world ocean, their importance on a global scale is great, because they are typically highly productive, and their state directly impacts mankind. As these areas can at no time be considered to be in a steady state (Smith \& Kemp 2001), there are few, if any, hydrodynamically stable time periods with uniform algal growth characteristics - periods whose production could be accurately estimated with less

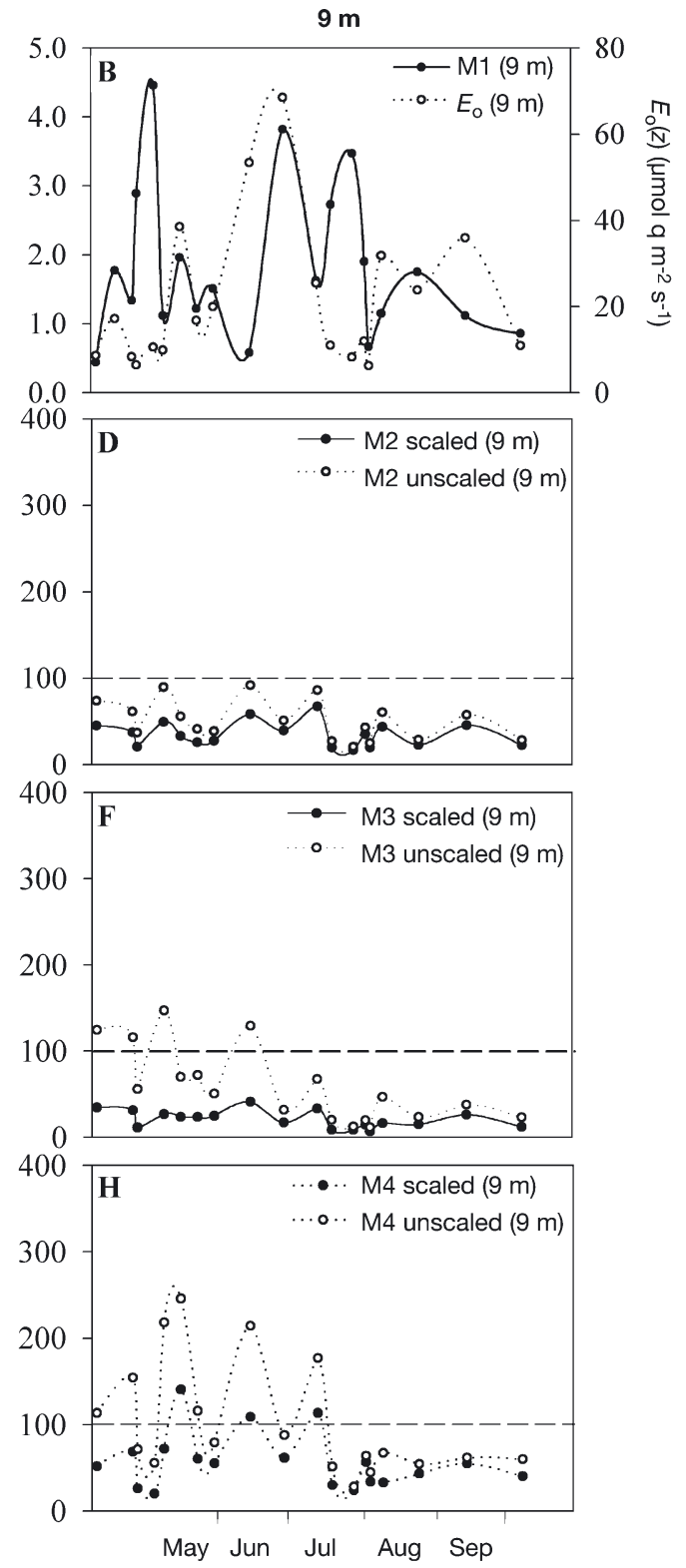

Fig. 8. Primary productivity at 3 and $9 \mathrm{~m}$ during study. $(\mathrm{A}, \mathrm{B}) \mathrm{P}_{\mathrm{M} 1}$ and $E_{\mathrm{o}}(\mathrm{z}) ;(\mathrm{C}-\mathrm{H}) \mathrm{P}_{\mathrm{M} 1}, \mathrm{P}_{\mathrm{M} 2}, \mathrm{P}_{\mathrm{M} 3}$ as \% of $\mathrm{P}_{\mathrm{M} 1}$ 
Table 3. Description of primary production (PP) models, and estimates of seasonal PP (SPP) ( $\mathrm{g} \mathrm{C} \mathrm{m}^{-2} \mathrm{yr}^{-1}$ ) based on models. Model descriptions: (a) PP approach, (b) light environment, and (c) absorption. SPPs: (i) in situ ${ }^{14} \mathrm{C}$ model, (ii) $\alpha$ and $\sigma_{\text {PSII }}$ scaled (original bio-optical models), (iii) $\alpha$ and $\sigma_{\text {PSII }}$ unscaled. Numbers in parentheses refer to percentage of M1. Note: for this comparison SPP estimates were calculated using only station-days on which both ${ }^{14} \mathrm{C}$ - and bio-optical measurements were made (Stns 2 , 5, 6, and 22 were excluded); hence, these values do not represent actual yearly production at study site

\begin{tabular}{|c|c|c|c|c|c|c|}
\hline \multirow{2}{*}{ Model } & \multicolumn{3}{|c|}{ Model descriptions } & \multicolumn{3}{|c|}{ - Model outcomes } \\
\hline & a & $\mathrm{b}$ & $\mathrm{C}$ & $\mathrm{i}$ & ii & iii \\
\hline M1 & C fixation & In vivo & All pigments & 77.2 & - & - \\
\hline M2 & C fixation & In vitro & All pigments & - & $62.1(80)$ & $70.8(92)$ \\
\hline M3 & $\mathrm{FRRF}+\mathrm{C}$ fixation & In vitro & Photosynthetic pigments & - & $55.6(72)$ & $101.0(131)$ \\
\hline M4 & FRRF & In vivo & Photosynthetic pigments & - & $128.5(166)$ & $182.7(237)$ \\
\hline
\end{tabular}

frequent sampling. Consequently, the interpolation of bio-optical parameters over seasons and/or depth intervals that are sparsely sampled-considered a weakness in PP modelling - (Bouman et al. 2000), introduces greater error in the results from such hydrodynamically labile areas compared to results from (e.g.) the central basins of the oceans. Coastal monitoring programme therefore need to provide higher temporal resolution of key parameters than programme in the open ocean.

A bio-optical PP model is most readily validated by comparing its outcome with that obtained by conventional PP techniques. However, such comparisons are somewhat complicated by the fact that the fixation of ${ }^{14} \mathrm{C}$ also has its uncertainties (Marra 2002), and thus cannot serve as an unambiguous basis for any comparison. Nevertheless, it seemed appropriate to consider ${ }^{14} \mathrm{C}$-based estimates as 'true' values and compare the bio-optical outcomes with them, because this technique is considered to estimate production directly and because the current understanding of PP in the world ocean is mostly based on ${ }^{14} \mathrm{C}$-measurements (Longhurst et al. 1995). The growth season in our study was representative of the productive state of this sea area; the SPP determined by M1, $85.9 \mathrm{~g} \mathrm{C} \mathrm{m}^{-2} \mathrm{yr}^{-1}$, was in accordance with the average SPP of $89 \mathrm{~g} \mathrm{C} \mathrm{m}^{-2} \mathrm{yr}^{-1}$ (range 65 to 141) measured in or near the study site from 1972 to 1990 (data retrieved from the data bank of the Finnish Institute of Marine Research; M. Raateoja unpubl.).

\section{Diverging vertical trends}

Whereas all the bio-optical models provided higher seasonally-integrated values than M1 near the surface, they displayed increasingly lower values than M1 with increasing depth. This can be attributed to at least 2 factors. First, the bio-optical models were tuned to closely follow underwater irradiance (as expected, $\mathrm{P}_{\mathrm{M} 1}$, which was based on actual ${ }^{14} \mathrm{C}$ incubations, did not do so). In particular, $\sigma_{\mathrm{PSII}}{ }^{\prime}$ - the photoadaptive variable in
M3 and M4 - could not account for the probable light inhibition near the surface due to the replacement of measurements made under 'the red light effect' with measurements not subjected to this effect (see below). This was partly the cause of the overestimates of $\mathrm{P}_{\mathrm{M} 3}$ and $\mathrm{P}_{\mathrm{M} 4}$ at $0 \mathrm{~m}$. Furthermore, unconverted $\phi_{\max }^{\mathrm{ps}}$ was justifiably used at 3 and $9 \mathrm{~m}$ (at irradiances near or below $E_{k}$ ), but a $3 \mathrm{~m}$ value of $\phi_{\max }^{\mathrm{ps}}$, or more specifically of $\alpha$, was used at $0 \mathrm{~m}$, where PP was probably limited by factors other than light during most station-days. This may have led to overestimates of $\mathrm{P}_{\mathrm{M} 3}$ at $0 \mathrm{~m}$, but to what extent, it is difficult to say, since we have no information about the mixing rates of the resident phytoplankton community in the surface mixed layer, nor as to whether the photoadaptation rates of the phytoplankton ever overcame this rate. Second, an artefact concerning near-surface in situ incubations arises by removing algae from an environment in which they were formerly freely circulating (Marra 2002). Keeping algae that are adapted to lower light levels at a constant high-light flux at $0 \mathrm{~m}$ during ${ }^{14} \mathrm{C}$-incubation causes them to undergo photoinhibition at rates that they probably do not experience in nature. This led to underestimates of $\mathrm{P}_{\mathrm{M} 1}$ at $0 \mathrm{~m}$ in our study.

Generally, bio-optical approaches are vulnerable to short-term variability in ambient irradiance at the time of the measurement, especially in near-surface layers. Varying cloudiness and sea swell, for instance, affect the representativeness and quality of ambient irradiance determinations. However, we minimized this source of error by scaling the ambient light regime at the time of the bio-optical determinations to the average light flux of the ${ }^{14} \mathrm{C}$-incubation period. Thus, we can conclude that the observed differences in the vertical patterns in the models were mainly due to the models themselves.

To estimate the effects of phytoplankton community structure on model estimates, we grouped the phytoplankton species data into different functional units (potential mixotrophs, motile species, Mesodinium rubrum). The seasonal variability in these groups was 
pronounced, as was the case for overall species composition (Fig. 4), but this organisation failed to explain any of the differing vertical trends between $\mathrm{P}_{\mathrm{M} 1}$ and the bio-optical PPs. Thus, it is concluded that neither algal species composition nor its functional characteristics explain the difference in the vertical trend of these approaches.

\section{Variable fluorescence-based model}

The main motivation for including an electron-flowbased model (M4) in this comparison was to discover how comparable are PP estimates acquired by the FRRF technique using the most realistic currentlyavailable values of the fixed components in Eq. (9). $\mathrm{P}_{\mathrm{M} 4}$ as an FRRF based PP outcome represents gross production (Kolber \& Falkowski 1993), and it is well known that the ${ }^{14} \mathrm{C}$-based value lies somewhere between net and gross production (Marra 2002). However, the $66 \%$ higher outcome of M4 compared to M1 seems high notwithstanding these facts, especially as the ${ }^{14} \mathrm{C}$-incubations were kept short in order to obtain PP estimates as close to gross production as possible.

The fixed components that convert the moles of electrons transported downstream of RCII to moles of fixed $\mathrm{C}\left(\phi_{\mathrm{C}^{\prime}} \mathrm{PQ}\right)$, and scale this amount of fixed $\mathrm{C}$ per mole of chl a $\left(n_{\text {PSII }}\right)$ make M4 rather an insensitive approach, because these parameters most probably demonstrate natural variability.

In particular, estimates of $\phi_{\mathrm{c}}$ and $n_{\mathrm{PSII}}$ for natural phytoplankton communities are scarce. A theoretical maximum value for $\phi_{\mathrm{c}}$ of 0.25 at irradiances under $E_{k}$ has generally been used (Kolber \& Falkowski 1993, Babin et al. 1996, Boyd et al. 1997). However, $\phi_{c}$ values as low as 0.14 to 0.19 have been observed (Kroon et al. 1993). We used a value of 0.18. Flameling \& Kronkamp (1998) measured the ratio of the quantum yields of $\mathrm{O}_{2}$ production to the charge separation for 4 microalgae, and a value of 0.18 equals an average value below $E_{k}$ interpreted from the graphical presentation by Flameling \& Kronkamp, multiplied by 2, since 1 quantum is needed for both of the RCs to transfer 1 electron from the water-splitting complex to the terminal electron acceptors. Values of $n_{\text {PSII }}$ from $1 / 800$ to $1 / 500$ have been used for eucaryotic microalgae (Kolber \& Falkowski 1993, Falkowski \& Kolber 1995, Boyd et al. 1997). Currently the performance of the FAST ${ }^{\text {tracka }}$ in determining in situ PP is dependent on the representativeness of these fixed parameters. Thus, representative estimates of these parameters for each oceanic region are required. This is particularly essential for the dynamic Baltic Sea, where the FRRF advantage of being able to evaluate photosynthetic parameters with a high spatial and temporal resolution is important.
Of the bio-optical models used, the P-E-based M2 seems to be the most reliable bio-optical model for the Baltic Sea environment, at least if compared with M1. Furthermore, it does not include any fixed parameters, and provides fairly reliable results even when no spectral scaling is possible. M3, including the FRRF based $\sigma_{\mathrm{PSII}}{ }^{\prime}$, requires spectral scaling. The fixed components in the calculations of PP, and sensitivity of the FRRF technique to the ambient red light in near-surface layers weaken the reliability of the results obtained with M4, and suggest that FRRF based estimates of PP should be viewed with caution.

\section{Seasonal patterns of bio-optical parameters}

The spectral distribution of the underwater light at our study site, and in the Baltic Sea in general, is greatly affected by CDOM concentrations (Højerslev 1988, Kirk 1994). Typically, maximum light transmission in the Baltic Sea is at 550 to $570 \mathrm{~nm}$ (e.g. Lindström 2000). Seasonality in light quality is largely determined by the absorption of terrestrial CDOM and phytoplankton. Due to high light attenuation, the euphotic layer, $z_{\mathrm{eu}}$ in the Baltic Sea is shallow: in our study it was always $<15 \mathrm{~m}$.

In spring, $z_{\mathrm{eu}}$ was considerably shallower than $z_{\mathrm{SML}}$, and consequently the vernal phytoplankton seemed to be low-light-acclimated. Specifically, the amount of photoprotective pigments was low in spring, and pigment-packaging amongst large diatom and dinoflagellate cells was high, as concluded from the spectral absorption measurements. The VABP showed lower levels of $\alpha$, but higher levels of $\phi_{\max }^{\mathrm{ph}}$ compared to the other periods in the growth season. Despite their high intrinsic quantum efficiency, the actual efficiency of vernal phytoplankton to utilise ambient light was lower than the efficiency of summer communities. Since the deep vernal surface mixed-layer leads to low average light levels being experienced by the algal community (Fig. 3), the low average chl a-specific primary productivity during VABP was to be expected ( $50 \%$ of the mean value of Stns 8 to 21; data not shown).

In summer, with more light in the mixed layer, pigment-packaging was rather low, while the amount of photoprotective carotenoids was relatively high. Chl a levels during LSBP were about half their values during the VABP, but production rates were approximately similar (Fig. 3). To some extent, the high $\bar{a}_{\mathrm{ph}}{ }^{*}$ levels during LSBP can explain this. Absorption by phycoerythrin, obviously by picocyanobacteria and cryptomonads (Seppälä et al. 2003), increases $\bar{a}_{\mathrm{ph}}{ }^{*}$ and $\bar{a}_{\mathrm{ps}}{ }^{*}$ considerably, as the phycoerythrin absorption-maximum matches the maximum light-transmission wavelength of 550 to $570 \mathrm{~nm}$ (J. Seppälä \& M. Raateoja unpubl.). 
The observed $\phi_{\max }^{\mathrm{ph}}$ range corresponded to only 4 to $21 \%$ ( $\phi_{\max }^{\mathrm{ps}} 8$ to $43 \%$ ) of the theoretical maximum value of $0.125 \mathrm{~mol} \mathrm{C}(\mathrm{mol} \mathrm{q})^{-1}$. Levels close to the theoretical maximum are, however, non-typical of an oceanic environment (Babin et al. 1995), and values of 0.07 to 0.09 are suggested to be the upper limit (Babin et al. 1995, Arbones et al. 2000). Taking into account photoreactions in Photosystem I (Myers 1980), electron sinks other than $\mathrm{CO}_{2}$ during photosynthetic light reaction (Laws 1991), as well as non-photochemical quenching mechanisms and almost perpetual nutrient stress, the observed values of $\phi_{\max }^{\mathrm{ph}}$ could be less than half of the theoretical maximum, as observed in a wide variety of aquatic systems (e.g. Lizotte \& Priscu 1994, Babin et al. 1996, Figueiras et al. 1999). Hence, the observed range of $\phi_{\max }^{\mathrm{ph}}$ is typical for an oceanic environment, in which algal photosynthesis is, to a varying extent, nutrientlimited (Figueiras et al. 1999, Johnson et al. 2002).

$\phi_{\max }$ is highly variable (Smith et al. 1989) and cannot be taken as constant for even a limited oceanic region (Sathyendranath et al. 1996), making it difficult to predict by models (Schofield et al. 1993). This was corroborated by our observations of an up to 2-fold vertical variability in $\phi_{\max }^{\mathrm{ph}}$ during a single station-day and an up to 3-fold variability between the station-days. This emphasizes the value of field-truth datasets of $\phi_{\max }^{\mathrm{ph}}$ for the refinement of bio-optical models.

\section{Spectral scaling}

Efficiency in converting incoming light energy into a chemical form is usually expressed either by apparent $\left(\alpha, P_{\max }\right)$ or intrinsic $\left(\phi_{\max }\right)$ photosynthetic efficiency. In either case, a determination of the algal photochemical response to light $(\alpha)$ is required. $\alpha$ is routinely measured under constant artificial light, and does not take natural variability in the light environment into account (Fig. 2). Consequently, spectral scaling of lightadaptive parameters is recommended if the natural light regime differs markedly from the light environment of the incubator (Sakshaug \& Slagstad 1991), and especially if seasonal variation in the spectral attenuation of light in the water column is pronounced. Regions experiencing the latter are, e.g., estuaries subject to seasonally-varying fresh-water input or coastal areas subject to seasonal algal biomass peaks. Our study site was actually a combination of the two.

The light environment of our incubator matched the natural light regime rather well (Fig. 2). Hence, leaving $\alpha$ spectrally unscaled raised the outcome of M2 only slightly. However, the seasonal variability in the $D_{\text {P-E }}$ value (average of 3 and $9 \mathrm{~m}$ ) was $41 \%$, and thus the spectral re-scaling of $\alpha$ was essential to obtain seasonally-comparable values for $\alpha$, and thus also for $\phi_{\max }^{\mathrm{ph}}$ and $\phi_{\max }^{\mathrm{ps}}$. The decreasing spectral matching between the light environment of the incubator and the natural light regime with increasing depth was apparently due to the effect of CDOM (J. Seppälä \& M. Raateoja unpubl.), as also suggested by Markager \& Vincent (2001) in their study on fresh-water systems.

Spectral scaling of variable fluorescence parameters cannot be regarded as an established practice since, as far as we know, only Suggett et al. (2001) have used this approach so far, employing $\bar{a}_{\mathrm{ph}}{ }^{*}$ for FRRF data. Whether spectral scaling improved the performance of M3 can only be speculated, as the spectrally-scaled and unscaled variants both produced an estimate that differed by $\sim 30 \%$ from M1, with most of the difference between the scaled and unscaled models deriving from $\sigma_{\text {PSII }}{ }^{\prime}$. We still believe that the spectral correction procedure was justified, because of the apparent mismatch between the light generated by FAST ${ }^{\text {tracka }}$ and the natural light field (Fig. 2).

Spectral scaling is normally carried out for total phytoplankton absorption (e.g. Markager \& Vincent 2001). Light absorbed by non-photosynthetic pigments may, however, contribute a large and variable portion of $a_{\mathrm{ph}}(\lambda)$, and therefore we performed scaling for photosynthetic absorption. When quantum-corrected and scaled against total absorption, the amount of photosynthetic absorption can be estimated using spectral fluorescence (Sakshaug et al. 1997). The scaling method is a rather critical step, and contains some uncertainties, especially when applied to natural samples, including species-specific differences in the absorption properties of PSI and PSII, and possible wavelength dependencies in energy transfer efficiency (Sakshaug et al. 1997).

\section{Applicability of FRRF technique to Case 2 waters}

While the large bulk of the field studies utilising FRRF metrics has been carried out in a truly oceanic environment, information on the applicability of the FRRF system to a more turbid environment is scarce. Our study area in the coastal Baltic Sea falls between Coastal Types 3 and 7 of the Jerlov classification (Jerlov 1976), depending on the time of the season growth (J. Seppälä \& M. Raateoja unpubl.). Here we consider aspects that should be taken into consideration when the FRRF system is used in a turbid environment categorised as a Case 2 water body.

\section{FRRF transients in near-surface layers}

Scattered ambient red light reaching the detector side of the FAST ${ }^{\text {tracka }}$ impedes the interpretation of the 
variable fluorescence data by flattening the variable fluorescence-transients in the near-surface layers. Consequently, the differentiation of the causes of the lowered $\phi$ between the photoinhibitory impact on the photosynthetic apparatus and the degradation of the FRRF signal becomes extremely difficult. We term this phenomenon the 'red light effect' (RLE).

We believe that the observed pattern above

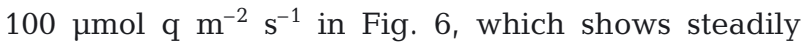
increasing noisiness in the modelling fit for the FRRF data towards higher $E_{\mathrm{d}}(z)$, reflects the RLE. Basically, the observed poorer fit can be caused by a decreased signal-to-noise ratio, but this was not the reason in this case. From our experience in the field, the signal-tonoise ratio in the FRRF data starts to decrease markedly at chl a levels $\sim 0.5 \mu \mathrm{g} \mathrm{l}^{-1}$. However, the chl $a$ levels were always $>1 \mathrm{\mu g} \mathrm{l}^{-1}$ in the upper $10 \mathrm{~m}$, with no significant decreasing trends towards the surface in the water column probed. This is far above the sensitivity threshold of the FAST ${ }^{\text {tracka }}$.

As the FAST ${ }^{\text {tracka }}$ has a single photomultiplier tube (PMT) serving both sides, the degradation in the fluorescence transients is not restricted to the ambient irradiance side, but also disturbs the measurements on the dark-adapted side (see also http://picasso.oce.orst. edu/ORSOO/FRRF). This characteristic is problematic in the water-column measurements, since there is no easy way of preventing the red photons from entering the PMT of the upward-facing instrument without simultaneously affecting the natural light field and the light-adaptative state of the algae. Moreover, there is no sure way of determining the exact depth below which the fluorescence measurements are reliable (Lizotte \& Priscu 1994).

The RLE probably represents a source of error in FRRF measurements in all kinds of aquatic systems, being mainly dependent on the level of ambient irradiance, but also on the optical properties of the water. The water layer affected by the RLE in our study was the upper 2 to $3 \mathrm{~m}$. In an oceanic environment, the thickness of the RLE layer has been observed to vary from 5 to $10 \mathrm{~m}$ (Suggett et al. 2001, Sosik \& Olson 2002). High $K_{d}(685)$ values from 0.62 to $0.72 \mathrm{~m}^{-1}$ explain the shallower RLE layer in our study.

Although the RLE penetrates deeper in the oceanic waters, its relative effect is probably not so pronounced as in more turbid waters, owing to the much shallower euphotic layers in the latter. The thickness of the RLE-layer in our study corresponded to 15 to $35 \%$ of the thickness of the euphotic layer, whereas in the oceans the corresponding percentage varies from 5 to $25 \%$, as suggested by the observed $z_{\text {eu }}$ of 40 to $80 \mathrm{~m}$ in these waters (Chipman et al. 1993, Mengelt et al. 2001). As the RLE occurs in that part of the water column where vertical variability in PP is greatest, it is a significant source of error when the water-column PP is determined by the FRRF technique. The reason why this effect did not lower M4 is simply that we did not include measurements clearly affected by the RLE, but replaced them with measurements from deeper layers.

FRRF transients in Case 2 waters

Light-harvesting by phytoplankton, excluding cyanophytes, is mainly performed by pigment-protein complexes comprised of chlorophylls and carotenoids (Jeffrey \& Vesk 1997). Consequently, the preferred light for photosynthesis is centred in the blue to green part of the visible spectrum. The excitation generated by the LED light source of the FAST ${ }^{\text {tracka }}$ is also centred in this region, and $95 \%$ of the whole quantum flux is within the range 458 to $514 \mathrm{~nm}$ (Fig. 2). Below the surface, 19 to $22 \%$ of PAR was within this range, depending on the station (data not shown). At $z_{\mathrm{eu}}$, the corresponding percentages decreased to $8-13 \%$ due to the optical characteristics of the Baltic Sea (high suspended load and CDOM load). The exception was VABP, with a value of $2 \%$. This particularly-biased light field arose from the combined effects of fresh-water runoff increasing turbidity and algal self-shading.

The FRRF measurement protocol overestimated the actual $\sigma_{\mathrm{PSII}}$ ' by providing light that is not found in situ in such proportions. The measured $\sigma_{\text {PSII }}$ overestimated the $\sigma_{\mathrm{PSII}}{ }^{\prime}$ in in situ light by 8 to $69 \%$ (average of 3 and $9 \mathrm{~m}$ ) during the phases of clearer water in mid-summer and autumn, and by 110 to $170 \%$ during VABP. Furthermore, the deeper the measurements, the more biased the estimates. This outcome differs markedly from the results of Suggett et al. (2001), who reported a corresponding range obtained in the North Atlantic of 23 to $48 \%$. Moreover, their results indicate that the excitation flux of the FAST ${ }^{\text {tracka }}$ resembled more closely the natural light field in deeper than in surface waters. This can be expected in central basins of the open ocean, where the water itself and the phytoplankton are the dominant absorbers of light. Our results are characteristic of aquatic systems subject to pronounced terrestrial influence. Re-scaling is needed because of the apparent mismatch between the light generated by the FAST ${ }^{\text {tracka }}$ and the natural light field of the Baltic Sea.

Although the light environment of our coastal study site does not strictly represent the pelagic Baltic Sea the conclusions of this study can be applied to the whole Baltic Sea, as well as to other aquatic systems subject to considerable loads of CDOM and/or suspended matter: coastal seas, estuaries and lakes, i.e. Case 2 waters. Our results suggest that active non-spectral bio-optical techniques should be applied to the Baltic Sea and optically-similar waters with caution. Further studies are 
required to assess the spectral correction factors for the FRRF transients in the pelagic Baltic Sea. These factors will probably lie somewhere between the present results and those obtained in the North Atlantic (Suggett et al. 2001). It is important to note that this issue does not concern photochemical energy conversion efficiency ( $\phi^{\prime}$ in our study), the most valuable variable fluorescence parameter for microalgal studies.

\section{Conclusions}

The Baltic Sea is subject to considerable terrestrial influence, and hence differs from the oceanic environment in its higher content of suspended matter and humic substances. These bias the underwater light regime and usually override phytoplankton and water itself as the dominant absorbers of light. High algal biomasses attenuate the available light even further by self-shading. Consequently, the light regime differs markedly from the bluish oceanic regime, and experiences considerable seasonal changes. This is true of several aquatic systems in addition to the Baltic Sea, including estuaries, coastal areas, and fresh-water systems. The results of this study on the re-scaling of FRRF parameters can provide a basis for future studies on Case 2 waters. Whenever bio-optical programmes are carried out in aquatic environments of this kind, light-adaptive variables determined under artificial light should be routinely matched to those in the natural light environment by spectral re-scaling, including parameters measured with an FRR fluorometer. Our results underline the need for the inclusion of spectral, not only bulk, radiometric measurements in monitoring programmes, especially as algal absorption characteristics are routinely determined spectrally.

The light source of the P-E incubator differed much less from the natural Baltic Sea light field than the light source of the FRR fluorometer. Consequently, $\alpha$ was less affected by spectral differences than $\sigma_{\mathrm{PSII}}$. The rescaling or non-scaling of $\sigma_{\text {PSII }}$ practically determined whether the bio-optical models including this parameter were able to reasonably reproduce the conventional estimate or not. The observed spectral mismatch raised the issue of whether the FRRF technique is able to produce reliable quantitative estimates of the photosynthetic electron flow in Case 2 waters without spectral corrections. This issue, as well as the shortcomings in probing the near-surface layers with FRRF metrics, should be taken into consideration whenever monitoring programmes utilising FRRF metrics are planned in aquatic systems categorised as Case 2 waters. Spectral mismatch is not such an important issue in oceanic waters, where most studies exploiting variable fluorescence metrics have been carried out so far.
Acknowledgements. We wish to thank Tvärminne Zoological Station, University of Helsinki, for offering laboratory facilities and time, and particularly E. Salminen and M. Sjöblom; S. Lehtinen of the Finnish Environment Institute for counting the samples; S. Laney for providing the v5LITE software; A. Herlevi and J. Ehn, University of Helsinki, for spectral light measurements, and R. King for improving the language. This study received financial support from the Maj and Tor Nessling Foundation, and the Onni Talas foundation for M.R., as well as from Academy of Finland and from the EU-project DANLIM (EVK3-CT2001-00049) for J. S.

\section{LITERATURE CITED}

Arbones B, Figueiras FG, Varela R (2000) Action spectrum and maximum quantum yield of carbon fixation in natural phytoplankton populations: implications for primary production estimates in the ocean. J Mar Syst 26:9-114

Babin M, Therriault JC, Legendre L, Nieke B, Reuter R, Condal A (1995) Relationship between the maximum quantum yield of carbon fixation and the minimum quantum yield of chlorophyll $a$ in vivo fluorescence in the Gulf of St. Lawrence. Limnol Oceanogr 40:956-968

Babin M, Morel A, Claustre H, Bricaud A, Kolber Z, Falkowski PG (1996) Nitrogen- and irradiance-dependent variations of the maximum quantum yield of carbon fixation in eutrophic, mesotrophic and oligotrophic marine systems. Deep-Sea Res 43:1241-1272

Bannister TT (1974) Production equations in terms of chlorophyll concentration, quantum yield, and upper limit to production. Limnol Oceanogr 19:1-12

Behrenfeld MJ, Falkowski PG (1997) A consumer's guide to phytoplankton productivity models. Limnol Oceanogr 42: 1479-1491

Behrenfeld MJ, Esaias WE, Turpie KR (2002) Assessment of primary production at the global scale. In: Williams PJleB, Thomas DN, Reynolds CS (eds) Phytoplankton productivity. Carbon assimilation in marine and freshwater ecosystems. Blackwell Science, Oxford, p 156-186

Bouman HA, Platt T, Kraay GW, Sathyendranath S, Irwin BD (2000) Bio-optical properties of the subtropical North Atlantic. I. Vertical variability. Mar Ecol Prog Ser 200:3-18

Boyd PW, Aiken J, Kolber Z (1997) Comparison of radiocarbon and fluorescence based (pump and probe) measurements of phytoplankton photosynthetic characteristics in the Northeast Atlantic Ocean. Mar Ecol Prog Ser 149:215-226

Bricaud A, Stramski D (1990) Spectral absorption coefficients of living phytoplankton and nonalgal biogenous matter: a comparison between the Peru upwelling area and the Sargasso Sea. Limnol Oceanogr 35:562-582

Carpenter EJ, Janson S, Boje R, Pollehne F, Chang J (1995) The dinoflagellate Dinophysis norvegica: biological and ecological observations in the Baltic Sea. Eur J Phycol 30: $1-9$

Chipman DW, Marra J, Takahashi T (1993) Primary production at $47^{\circ} \mathrm{N}$ and $20^{\circ} \mathrm{W}$ in the North Atlantic Ocean: a comparison between the ${ }^{14} \mathrm{C}$ incubation method and the mixed layer carbon budget. Deep-Sea Res 40:151-169

Cleveland JS, Weidemann AD (1993) Quantifying absorption by aquatic particles: a multiple scattering correction for glass-fibre filters. Limnol Oceanogr 38:1321-1327

Falkowski PG, Kolber Z (1995) Variations in chlorophyll yields in phytoplankton in the world oceans. Aust J Plant Physiol 22:341-355

Falkowski PG, Raven JA (1997) Aquatic photosynthesis. Blackwell Science, Oxford 
Figueiras FG, Arbones B, Estrada M (1999) Implications of bio-optical modeling of phytoplankton photosynthesis in Antarctic waters: further evidence of no light limitation in the Brandsfield Strait. Limnol Oceanogr 44:1599-1608

Flameling IA, Kronkamp J (1998) Light dependence of quantum yields for PSII charge separation and oxygen evolution in eukaryotic algae. Limnol Oceanogr 43: 284-297

Haapala J (1994) Upwelling and its influence on nutrient concentration in the coastal area of the Hanko peninsula, entrance of the Gulf of Finland. Estuar Coast Shelf Sci 38: $507-521$

Harding LW Jr, Meeson BW, Prézelin BB, Sweeney BM (1981) Diel periodicity of photosynthesis in marine phytoplankton. Mar Biol 61:95-105

Harding LW Jr, Meeson BW, Tyler MA (1983) Photoadaptation and diel periodicity of photosynthesis in the dinoflagellate Prorocentrum mariae-lebouriae. Mar Ecol Prog Ser 13:73-85

Harding LW Jr, Mallonee ME, Perry ES (2002) Toward a predictive understanding of primary productivity in a temperate, partially stratified estuary. Estuar Coast Shelf Sci 55:437-463

Højerslev NK (1988) Natural occurrences and optical effects of gelbstoff. Rep Inst Phys Oceanogr Univ Cph 50

Jassby AD, Platt T (1976) Mathematical formulation of the relationship between photosynthesis and light for phytoplankton. Limnol Oceanogr 21:540-547

Jeffrey SW, Vesk M (1997) Introduction to marine phytoplankton and their pigment signatures. In: Jeffrey SW, Mantoura RFC, Wright SW (eds) Phytoplankton pigments in oceanography: guidelines to modern methods. UNESCO, Paris, p 37-82

Jerlov NG (1976) Marine optics. Elsevier Oceanogr Ser 14. Elsevier, Amsterdam

Jespersen AM, Christoffersen K (1987) Measurements of chlorophyll-a from phytoplankton using ethanol as extraction solvent. Arch Hydrobiol 109:445-454

Johnsen G, Sakshaug E (1996) Light harvesting in bloomforming marine phytoplankton, species-specificity and photoacclimation. Sci Mar 60 (Suppl 1):47-56

Johnson Z, Bidigare RR, Goericke R, Marra J, Trees C, Barber RT (2002) Photosynthetic physiology and physicochemical forcing in the Arabian Sea, 1995. Deep-Sea Res 49: 415-436

Kaczmarek S, Woźniak B (1995) The application of the optical classification of waters in the Baltic Sea (Case 2 waters). Oceanologia 37:285-298

Keller AA, Taylor C, Oviatt C, Dorrington T, Holcombe G, Reed L (2001) Phytoplankton production patterns in Massachusetts Bay and the absence of the 1998 winterspring bloom. Mar Biol 138:1051-1062

Kiefer DA, Mitchell BG (1983) A simple, steady state description of phytoplankton growth based on absorption cross section and quantum yield. Limnol Oceanogr 28: $770-776$

Kirk JTO (1994) Light and photosynthesis in aquatic systems, 2nd edn. Cambridge University Press, Cambridge, UK

Kolber ZS, Falkowski PG (1993) Use of active fluorescence to estimate phytoplankton photosynthesis in situ. Limnol Oceanogr 38:1646-1665

Kolber ZS, Prášil O, Falkowski PG (1998) Measurements of variable fluorescence using fast repetition rate techniques: defining methodology and experimental protocols. Biochim Biophys Acta 1367:88-106

Kononen K, Kuparinen J, Mäkelä K, Laanemets J, Pavelson J, Nômmann S (1996) Initiation of cyanobacterial blooms in a frontal region at the entrance to the Gulf of Finland. Limnol Oceanogr 41:98-112

Kononen K, Huttunen M, Kanoshina I, Laanemets J, Moisander P, Pavelson J (1999) Spatial and temporal variability of a dinoflagellate-cyanobacterium community under a complex hydrodynamical influence: a case study at the entrance to the Gulf of Finland. Mar Ecol Prog Ser 186: $43-57$

Kononen K, Huttunen M, Hällfors S, Gentien P and 6 others (2003) Development of a deep chlorophyll maximum of Heterocapsa triquetra Ehrenb. at the entrance to the Gulf of Finland. Limnol Oceanogr 48:594-607

Kopf U, Heinze J (1984) 2, 7-bis(diethylamino)phenazoxonium chloride as a quantum counter for emission measurements between 240-700 nm. Anal Chem 56:1931-1935

Krause GH, Weis E (1991) Chlorophyll fluorescence and photosynthesis: the basics. Annu Rev Plant Physiol Plant Mol Biol 42:313-349

Kroon B, Prézelin BB, Schofield O (1993) Chromatic regulation of quantum yields for photosystem II charge separation, oxygen evolution, and carbon fixation in Heterocapsa pygmaea (Pyrrophyta). J Phycol 29:453-462

Kuparinen J (1984) Annual and seasonal fluctuation of primary productivity and overall respiration in a pelagic plankton community off Tvärminne, SW coast of Finland. Ophelia (Suppl 3):111-122

Kuparinen J (1985) Comparison of the oxygen and 14C methods to measure phytoplankton production rates: evaluation of the photosynthetic quotient. Verh Int Ver Theor Angew Limnol 22:2208-2213

Kuparinen J (1987) Production and respiration of overall plankton and ultraplankton communities at the entrance to the Gulf of Finland in the Baltic Sea. Mar Biol 93: 591-607

Kuparinen J, Kuosa H (1993) Autotrophic and heterotrophic picoplankton in the Baltic Sea. Adv Mar Biol 29:73-128

Kuparinen J, Leppänen JM, Sarvala J, Sundberg A, Virtanen A (1984) Production and utilisation of organic matter in a Baltic ecosystem off Tvärminne, southwest coast of Finland. Rapp P-V Réun Cons Int Explor Mer 183:180-192

Laws EA (1991) Photosynthetic quotients, new production and net community production in the open ocean. DeepSea Res 38:143-167

Lewis MR, Warnock RE, Irwin B, Platt T (1985) Measuring photosynthetic action spectra of natural phytoplankton populations. J Phycol 21:310-315

Lindström M (2000) Seasonal changes in the underwater light milieu in a Finnish Baltic Sea coastal locality. Geophysica 36:215-232

Lizotte MP, Priscu JP (1994) Natural fluorescence and quantum yields in vertically stationary phytoplankton from perennially ice-covered lakes. Limnol Oceanogr 39: $1399-1410$

Longhurst A, Sathyendranath S, Platt T, Caverhill C (1995) An estimate of global primary production in the ocean from satellite radiometer data. J Plankton Res 17:1245-1271

Markager S, Vincent WF (2001) Light absorption by phytoplankton: development of a matching parameter for algal photosynthesis under different light regimes. J Plankton Res 23:1373-1384

Marra J (2002) Approaches to the measurement of plankton production. In: Williams PJleB, Thomas DN, Reynolds CS (eds) Phytoplankton productivity. Carbon assimilation in marine and freshwater ecosystems, Blackwell Science, Oxford, p 78-108

Mengelt C, Abbott MR, Barth JA, Letelier RM, Measures CI, Vink S (2001) Phytoplankton pigment distribution in rela- 
tion to silicic acid, iron and the physical structure across the Antarctic Polar Front, $170^{\circ} \mathrm{W}$, during austral summer. Deep-Sea Res 48:4081-4100

Mitchell BG, Kiefer DA (1988) Chlorophyll a specific absorption and fluorescence excitation spectra for light-limited phytoplankton. Deep-Sea Res 35:639-663

Morel A, Prieur L (1977) Analysis of variations in ocean color. Limnol Oceanogr 22:709-722

Myers J (1980) On the algae: thoughts about physiology and measurements of efficiency. In: Falkowski PG (ed) Primary productivity in the sea, Plenum, New York, p 1-16

Neori A, Vernet M, Holm-Hansen O, Haxo FT (1988) Comparison of chlorophyll far-red and red fluorescence excitation spectra with photosynthetic oxygen action spectra for photosystem II in algae. Mar Ecol Prog Ser 44: 297-302

Niemi M, Kuparinen J, Uusi-Rauva A, Korhonen K (1983) Preparation of ${ }^{14} \mathrm{C}$-labeled algal samples for liquid scintillation counting. Hydrobiologia 106:149-156

Oxborough KO, Baker NR (1997) Resolving chlorophyll a fluorescence images of photosynthetic efficiency into photochemical and non-photochemical components calculation of $\mathrm{qP}$ and $\mathrm{Fv}^{\prime} / \mathrm{Fm}^{\prime}$ without measuring $\mathrm{Fo}^{\prime}$. Photosynth Res 54:135-142

Platt T, Sathyendranath S (1999) Spatial structure of pelagic ecosystem processes in the global ocean. Ecosystems 2: 384-394

Raateoja M, Seppälä J (2001) Light utilisation and photosynthetic efficiency of Nannochloris sp. (Chlorophyceae) approached by spectral absorption characteristics and fast repetition rate fluorometry (FRRF). Boreal Environ Res 6: 205-221

Sagan S, Dera J (1994) Patchiness in the Baltic Sea in terms of optical properties. Int Counc Explor Sea Coop Res Rep 201:109-115

Sakshaug E, Slagstad D (1991) Light and productivity in polar marine ecosystems: a physiological view. Polar Res 10: 69-85

Sakshaug E, Johnsen G, Andresen K, Vernet M (1991) Modeling of light-dependent algal photosynthesis and growth: experiments with the Barents Sea diatoms Thalassiosira nordenskioldeii and Chaetoceros furcellatus. Deep-Sea Res 38:415-430

Sakshaug E, Bricaud A, Dandonneau Y, Falkowski PG and 5 others (1997) Parameters of photosynthesis: definitions, theory and interpretation of results. J Plankton Res 19: 1637-1670

Sathyendranath S, Platt T, Stuart V, Irwin BD, Feldhuis MJW, Kraay BW, Harrison WG (1996) Some bio-optical

Editorial responsibility: Otto Kinne (Editor),

Oldendorf/Luhe, Germany characteristics of phytoplankton in the NW Indian Ocean. Mar Ecol Prog Ser 132:299-311

Schofield O, Bidigare RR, Prézelin B (1990) Spectral photosynthesis, quantum yield and blue-green light enhancement of productivity rates in the diatom Chaetoceros cracile and the prymnesiophyte Emiliania huxleyi. Mar Ecol Prog Ser 64:175-186

Schofield O, Prézelin B, Bidigare RR, Smith RC (1993) In situ photosynthetic quantum yield. Correspondence to hydrographic and optical variability within the Southern California Bight. Mar Ecol Prog Ser 93:25-37

Seppälä J, Ylöstalo P, Kuosa H (2003) Spectral absorption and fluorescence characteristics of phytoplankton in different size fractions across a salinity gradient in the Baltic Sea. Int J Remote Sens (in press)

Smith EM, Kemp WM (2001) Size structure and the production/respiration balance in a coastal plankton community. Limnol Oceanogr 46:473-485

Smith RC, Prézelin BB, Bidigare RR, Baker KS (1989) Biooptical modelling of photosynthetic production in coastal waters. Limnol Oceanogr 34:1524-1544

Sosik HM, Olson RJ (2002) Phytoplankton and iron limitation of photosynthetic efficiency in the Southern Ocean during late summer. Deep-Sea Res 49:1195-1216

Steemann Nielsen E (1952) The use of radioactive carbon $\left({ }^{14} \mathrm{C}\right)$ for measuring organic production in the sea. J Cons Int Explor Mer 18:117-140

Stuart V, Sathyendranath S, Head EJH, Platt T, Irwin B, Maass H (2000) Bio-optical characteristics of diatom and prymnesiophyte populations in the Labrador Sea. Mar Ecol Prog Ser 201:91-106

Suggett D, Kraay G, Holligan P, Davey M, Aiken J, Geider R (2001) Assessment of photosynthesis in a spring cyanobacterial bloom by use of a fast repetition rate fluorometer. Limnol Oceanogr 46:802-810

Utermöhl H (1958) Zur Vervollkommnung der quantitativen Phytoplankton Methodik. Mitt Int Ver Theor Angew Limnol 9:1-38

Vaillancourt RD, Marra J, Barber RT, Smith WO Jr (2003) Primary productivity and in situ quantum yields in the Ross Sea and Pacific sector of the Antarctic Circumpolar Current. Deep-Sea Res 50:559-578

Voipio A (1981) The Baltic Sea. Elsevier Oceanogr Ser 30. Elsevier, Amsterdam

Webb WL, Newton M, Starr D (1974) Carbon dioxide exchange of Alnus rubra: a mathematical model. Oecologia $17: 281-291$

Yentsch CS (1962) Measurement of visible light absorption by particulate matter in the ocean. Limnol Oceanogr 7:207-217

Submitted: April 23, 2003; Accepted: August 30, 2003

Proofs received from author(s): January 19, 2004 